\title{
LMPI-augmented kappa intron enhancer activity contributes to upregulation expression of Ig kappa light chain via NF-kappaB and AP-I pathways in nasopharyngeal carcinoma cells
} \author{
HaiDan Liu'1,2, Hui Zheng ${ }^{1}$, Zhi Duan ${ }^{1}$, DuoSha Hu${ }^{1}$, Ming Li ${ }^{1}$, SuFang Liu ${ }^{1}$, \\ ZiJian Li ${ }^{1}$, XiYun Deng ${ }^{1}$, ZhenLian Wang ${ }^{1}$, Min Tang ${ }^{1}$, Ying Shi ${ }^{1}$, Wei $\mathrm{Yi}^{1}{ }^{1}$ and \\ Ya Cao*1
}

Address: ${ }^{1}$ Cancer Research Institute, Xiangya School of Medicine, Central South University, Xiangya Road 110, Changsha, Hunan 410078, PR China and ${ }^{2}$ Center of Clinical Gene Diagnosis and Therapy, The Second Xiangya Hospital of Central South University, Renmin Road 139, Changsha, Hunan 410011, PR China

Email: HaiDan Liu - lhd1129@126.com; Hui Zheng - zhenghui@163.com; Zhi Duan - karilinduan@gmail.com;

DuoSha Hu - dorsalvip@hotmail.com; Ming Li - liming67@tom.com; SuFang Liu - sufang_liu@126.com; ZiJian Li - lzjany@gmail.com;

XiYun Deng - deng_xiyun@yahoo.com; ZhenLian Wang - wangzhenlian1980@126.com; Min Tang - tangmin08@gmail.com;

Ying Shi - sy2jp@hotmail.com; Wei Yi - yw2zyh2000@hotmail.com; Ya Cao* - ycao98@public.cs.hn.cn

* Corresponding author

Published: 27 October 2009

Molecular Cancer 2009, 8:92 doi:10.1 186/1476-4598-8-92
Received: 26 April 2009

Accepted: 27 October 2009

This article is available from: http://www.molecular-cancer.com/content/8/I/92

(C) 2009 Liu et al; licensee BioMed Central Ltd.

This is an Open Access article distributed under the terms of the Creative Commons Attribution License (http://creativecommons.org/licenses/by/2.0), which permits unrestricted use, distribution, and reproduction in any medium, provided the original work is properly cited.

\begin{abstract}
Background: Expression of kappa gene is under the control of distinct cis-regulatory elements, including the kappa intron enhancer ( $\left.\mathrm{iE}_{k}\right)$ and the kappa $3^{\prime}$ enhancer $\left(3^{\prime} \mathrm{E}_{k}\right)$. The active enhancers and expression of immunoglobulin is generally considered to be restricted to $B$ lymphocytes. However, accumulating evidence indicated that epithelial cancer cells, including nasopharyngeal carcinoma (NPC) cell lines, express immunoglobulins. The mechanisms underlying the expression of lgs in nonlymphoid cells remain unknown. On the basis of our previous finding that expression of kappa light chain in NPC cells can be upregulated by EBV-encoded latent membrane protein I (LMPI) through the activation of NF-KB and AP-I signaling pathways, we thus use NPC cells as model to further explore the molecular mechanisms of nonlymphoid cells expressing Ig kappa.
\end{abstract}

Results: In this study, luciferase reporter plasmid containing human wild-type $\mathrm{iE}_{\kappa}$, and its derivative plasmids containing mutant binding sites for transcription factor NF- $\mathrm{KB}$ or AP-I were constructed. Luciferase reporter assays demonstrate $\mathrm{iE}_{\kappa}$ is active in IgK-expressing NPC cells and LMPI expression can upregulate the activity of $\mathrm{iE}_{\kappa}$ in NPC cells. Mutation of the NF- $\kappa B$ or AP-I site within and downstream the $\mathrm{iE}_{\mathrm{K}}$, inhibition of the NF- $\mathrm{KB}$ and AP-I pathways by their respective chemical inhibitor Bay I I-7082 and SP600 I 25 as well as stable or transient expression of dominant-negative mutant of $I_{\kappa} B \alpha(D N M I \kappa B \alpha)$ or of c-Jun (TAM67) indicate that both sites are functional and LMPIenhanced $\mathrm{iE}_{\kappa}$ activity is partly regulated by these two sites. Gel shift assays show that LMPI promotes NF- $\mathrm{KB}$ subunits $\mathrm{p} 52$ and $\mathrm{p} 65$ as well as AP-I family members c-Jun and c-Fos binding to the $\kappa N F-\kappa B$ and the $\kappa A P-I$ motifs in vitro, respectively. Both chemical inhibitors and dominant negative mutants targeting for NF-KB and AP-I pathways can attenuate the LMPI-enhanced bindings. Co-IP assays using nuclear extracts from HNE2-LMPI cells reveal that $p 52$ and $p 65$, c-Jun and c-Fos proteins interact with each other at endogenous levels. ChIP assays further demonstrate 
p52 and $p 65$ binding to the $\kappa B$ motif as well as c-Jun and c-Fos binding to the AP-I motif of Ig kappa gene in vivo.

Conclusion: These results suggest that human $\mathrm{iE}_{\kappa}$ is active in lgא-expressing NPC cells and LMPIstimulated NF- $\kappa B$ and $A P-I$ activation results in an augmenting activation of the $i E_{\kappa}$. LMPI promotes the interactions of heterodimeric NF- $\mathrm{KB}(\mathrm{p} 52 / \mathrm{p} 65)$ and heterodimeric AP-I (c-Jun/cFos) transcription factors with the human $\mathrm{iE}_{\mathrm{K}}$ enhancer region are important for the upregulation of kappa light chain in LMPI-positive nasopharyngeal carcinoma cells.

\section{Background}

While considerable evidence has shown that immunoglobulins (Igs) "unexpectly" expressed in malignant tumors of epithelial origin [1-10], much less is known about the molecular mechanisms of nonlymphoid cells expressing Igs. In our previous work, we have also demonstrated that nonlymphoid NPC cells express immunoglobulin kappa light chain. In addition, we have found that EBV-encoded latent membrane protein 1 (LMP1) can upregulate the expression of kappa light chain in NPC cells and both NF- $\kappa \mathrm{B}$ and AP-1 signaling pathways are involved in LMP1-augmented kappa light chain expression [1]. These results promote us using of NPC cell lines as model to further explore the mechanisms underlying the expression of Ig kappa in nonlymphoid cells.

Expression of kappa light chain gene is under the control of distinct cis-regulatory elements, including the kappa intron enhancer ( $\mathrm{iE}_{\mathrm{\kappa}}$ ) and the kappa 3 ' enhancer (3' $\mathrm{E}_{\mathrm{\kappa}}$ ) $[11,12]$, which are located within the $J_{\kappa}-C_{\kappa}$ region and downstream of $C_{\kappa}$ region, respectively. Both enhancers are inactive at the pro- $\mathrm{B}$ and pre- $\mathrm{B}$ cell stages and active at the Igא-expressing mature $\mathrm{B}$ cell and plasma cell stages. The activity of these enhancers in other non-kappa-producing cell lineages, such as T-lymphoid cells, epithelial cells and NIH3T3 fibroblasts, is generally silent $[11,13]$. Base on these, it is generally believed that the activation of $\mathrm{iE}_{\mathrm{\kappa}}$ and 3 ' $\mathrm{E}_{\kappa}$ is required for immunoglobulin kappa gene expression and is $B$ cell lineage-restricted events [14,15]. An interesting feature of kappa gene transcription is its inducibility. Certain agents, such as cycloheximide (CYC), phorbol esters and bacterial product lipopolysaccharide (LPS) can induce the activation of kappa enhancers and result in kappa gene expression at the pre-B cell stage [16]. Nucleation of transcription factors PU.1, PIP, c-Fos and cJun on the kappa 3' enhancer core can cause a very dramatic induction in $3^{\prime} \mathrm{E}_{\mathrm{K}}$ activity in NIH3T3 fibroblasts, a cell in which the enhancer is normally silent [13]. These findings reinforce the possibility of nonlymphoid cells expressing Ig kappa by certain unidentified mechanisms and suggest that other extracellular factors, such as gene products encoded by viruses, are also likely to induce kappa enhancers' activation, finally result in kappa gene transcription and expression.
One viral protein, latent membrane protein 1, is considered as a major oncogenic protein encoded by EBV for its transform and tumorigenic activities and is found to be able to transform cell lines and alter the phenotype of cells due to its oncogenic potential [17]. Biologically, LMP1 is an integral membrane protein with six transmembrane segments that facilitate self-aggregation in the plasma membrane and transduces ligand-independent signals, including NF- $\kappa \mathrm{B}, \mathrm{c}$-Jun- $\mathrm{NH}_{2}$-terminal kinase (JNK), p38/ MAPK, Ras/MEK/ERK/MAPK, PI3K/Akt and JAK/STAT [18-23]. The nuclear factor $\kappa \mathrm{B}(\mathrm{NF}-\kappa \mathrm{B})$ and c-Jun N-terminal kinase (JNK) signaling pathways are the most important, since their activation results in the overexpression of most LMP1 target genes [24]. LMP1 can mimic CD40 signaling to induce $\mathrm{B}$ cell activation and differentiation in vivo. They share some molecules such as TRAF1, 2, 3, and 5 as signal transducers as well as some pathways such as NF- $\kappa$ B, JNK, p38/MAPK, PI3K/Akt and JAK/STAT pathways [25]. In normal B cells, an important mechanism of Ig production is CD40 ligation-triggered cellular signaling pathways [26]. In addition, it has been found that CD40 signaling can increase IgH 3 ' enhancer activity [27]. These studies, in combination with our previous finding that kappa light chain is significantly higher in LMP1-positive than in LMP1-negative NPC cells [1], we thus speculate that upregulation the expression of kappa light chain by LMP1 may be the result of LMP1-induced kappa enhancer's activation in NPC cells.

The function of enhancers is mediated by DNA binding proteins that recruit to the enhancer [12]. Multiple protein binding sites have been identified and characterized in each of the kappa enhancers. $\mathrm{A} \kappa \mathrm{B}$ binding site within the $\mathrm{iE}_{\mathrm{\kappa}}$ and the activity of $\mathrm{iE}_{\mathrm{\kappa}}$ is mainly dependent on the nuclear factor NF- $\kappa \mathrm{B}$ binding to $\kappa \mathrm{B}$ element $[28,29]$. Deletion or mutation of the $\kappa \mathrm{B}$ site abolishes the activity of $\mathrm{iE}_{\mathrm{K}^{\prime}}$ suggesting it might as a crucial enhancer element $[16,30]$. In addition, the human kappa gene $\mathrm{J}_{\kappa}-\mathrm{C}_{\kappa}$ region also contains a perfect consensus AP-1 site, which located 320 bases downstream of the $\kappa \mathrm{B}$ site. The $\kappa \mathrm{AP}-\mathrm{l}$ site in the context of the $\mathrm{iE}_{\mathrm{\kappa}}$ can positively regulate the $\mathrm{iE}_{\mathrm{\kappa}}$ activity and kappa expression in B cells, suggests that it plays a role in kappa gene regulation [31]. However, in Igא-expressing nonlymphoid cells, whether these two binding sites play roles in functional activation of $\mathrm{iE}_{\kappa}$ is still unknown. 
Since kappa enhancers' activation is required for Ig kappa gene expression and their activations are generally considered as $\mathrm{B}$ cell lineage-restricted events, and since NF- $\mathrm{KB}$ and AP-1 binding sites exist within and downstream the $\mathrm{iE}_{\mathrm{k}}$ enhancer, and on the basis of our previous findings that both NF-kB and AP-1 pathways are involved in LMP1-augmented Ig kappa expression in human NPC cells, we therefore focus on the $\mathrm{iE}_{\mathrm{k}}$ enhancer and attempt to study further whether it is active in Igא-expressing NPC cells and whether LMP1-upregulated kappa expression is correlated with the activation of $\mathrm{iE}_{\mathrm{\kappa}}$ via NF- $\mathrm{kB}$ and AP-1 pathways. In this study, luciferase reporter analysis demonstrate that the $\mathrm{iE}_{\mathrm{k}}$ whose activation is required for immunoglobulin kappa gene expression indeed activates in Igк-expressing NPC cells and stable or transient LMP1 expression can upregulate the activity of $\mathrm{iE}_{\mathrm{K}}$ in NPC cells. Moreover, mutation analysis of $\kappa \mathrm{B}$ or $\mathrm{AP}-1$ binding site within or downstream the $\mathrm{iE}_{\kappa^{\prime}}$ inhibition of LMP1-mediated NF- $\mathrm{KB}$ and AP-1 signaling pathways by using specific chemical inhibitors and dominant inhibitory molecules indicate that both sites are functional and LMP1enhanced $\mathrm{iE}_{\mathrm{K}}$ activity is regulated, to some extent, through these two sites. Gel shift assays show that LMP1 promotes NF- $\mathrm{KB}$ subunits $\mathrm{p} 52$ and p 65 as well as AP-1 family members $\mathrm{c}-J u n$ and c-Fos binding to the $\kappa \mathrm{NF}-\mathrm{\kappa B}$ and the $\mathrm{\kappa AP}$ 1 motifs in vitro, respectively. Both chemical inhibitors and dominant negative mutants targeting for NF- $\mathrm{KB}$ and $\mathrm{AP}-1$ pathways can attenuate theLMP1-enhanced bindings. Co-IP assays using nuclear extracts from HNE2LMP1 cells reveal that p52 and p65, c-Jun and c-Fos proteins interact with each other at endogenous levels. ChIP assays further demonstrate $\mathrm{p} 52$ and $\mathrm{p} 65$ binding to the $\kappa \mathrm{B}$ motif as well as c-Jun and c-Fos binding to the AP-1 motif of Ig kappa gene in vivo. Based on the findings reported here, we conclude that the $\mathrm{iE}_{\mathrm{K}}$ enhancer is active in NPC cells and is further activated by LMP1 via NF- $\kappa B$ and AP-1 pathways, which contributes to the upregulation of Ig kappa by LMP1 in NPC cells.

\section{Results}

Activation of the human immunoglobulin kappa intron enhancer in Ig -expressing nasopharyngeal carcinoma cells Immunoglobulin kappa gene expression is under the control of distinct cis-regulatory elements, including the $\mathrm{iE}_{\mathrm{k}}$ and the $3^{\prime} \mathrm{E}_{\mathrm{K}}[11,12]$. The activity of these enhancers is believed to contribute to Ig kappa expression in B cell lines [14]. In order to investigate if the $\mathrm{iE}_{\mathrm{K}}$ enhancer could be functionally activated in NPC cells, we linked the $\mathrm{iE}_{\kappa}$ to the I $\alpha$-promoter driving the transcription of the luciferase reporter gene and analyzed this reporter construct in transient transfection of NPC cell lines. A schematic diagram of the Ig kappa intron enhancer regions that were cloned was shown in Fig. 1A, and the wild-type reporter construct was illustrated in Fig. 1B. As shown in Fig. 1B, a 575 bp genomic fragment containing the intact $\mathrm{iE}_{\mathrm{k}}$ was subcloned into the enhancerless pGL3- $\alpha$ plasmid. This construct, which containing wild-type $\kappa \mathrm{B}$ site within the $\mathrm{iE}_{\kappa}$ and wild-type AP-1 site downstream the 3' flank of the $\mathrm{iE}_{\mathrm{k}}$ (designated as $p \alpha-i E_{\kappa} w t$ ), was introduced into HNE2 and HNE2-LMP1 cells to test the activity of $\mathrm{iE}_{\mathrm{K}}$. The human $\mathrm{I} \alpha$ promoter we used was identical to that used previously [32] and we found it to be minimally affected by LMP1 in our experiments (Fig. 1, C and 1D). Transfection of p $\alpha-$ $\mathrm{iE}_{\mathrm{K}} \mathrm{wt}$ generated higher luciferase activities than that of the pGL3- $\alpha$ construct whether in LMP1-negative $(\mathrm{P}<0.01)$ or in LMP1-positive $(\mathrm{P}<0.01)$ NPC cells (Fig. 1, C and 1D). Notably, the luciferase activity of pGL3- $\alpha$ in both HNE2 and HNE2-LMP1 cells was essentially equivalent, which suggested that the functional specificities of the $\mathrm{iE}_{\mathrm{k}}$ enhancer in NPC cells were due to the enhancer itself rather than the promoter sequences. These results indicate that the $\mathrm{iE}_{\kappa}$ is active in NPC cells which express immunoglobulin kappa light chain.

\section{Increases the activity of human immunoglobulin kappa intron enhancer by LMPI in nasopharyngeal carcinoma cells}

We found previously that EBV-LMP1 upregulates Ig kappa light chain expression in nasophayngeal epithelial cells [1]. In order to investigate whether the upregulation effect was due to LMP1-enhannced $\mathrm{iE}_{\kappa}$ activity, luciferase reporter assays were performed to compare the $\mathrm{iE}_{\kappa}$ activity in LMP1-positive and -negative NPC cells. The results indicated that the activity of $\mathrm{iE}_{\mathrm{K}}$ in HNE2-LMP1 cells was significantly higher than that in HNE2 cells (Fig. 1C, 53.5 vs. $17.7, \mathrm{P}<0.01$ ), which was in line with the kappa chain expression patterns of these two cell lines [1]. Similar results were obtained with transient transfection of LMP1 into HNE2 cells (Fig. 1D). These results indicate that LMP1 can enhance the $\mathrm{iE}_{\mathrm{k}}$ activity. We thus infer that LMP1 can increase the activity of $\mathrm{iE}_{\mathrm{\kappa}}$ and the upregulation of kappa light chain by LMP1 is likely due to increase the activity of $\mathrm{iE}_{\mathrm{K}}$ by LMP1.

\section{Involvement of NF- B and AP-I signaling pathways in LMPI-increased human kappa intron enhancer activity}

Based on the previous finding that both NF- $\mathrm{KB}$ and AP-1 signaling pathways are involved in LMP1-augmented kappa light chain expression [1], to determine whether either the NF- $\mathrm{KB}$ or the AP-1 sequence was required for LMP1-enhanced $\mathrm{iE}_{\mathrm{K}}$ activity, site-directed mutagenesis by overlap extension PCR was used to introduce mutations into each of these sequences. From the $\mathrm{p} \alpha-\mathrm{iE}_{\mathrm{k}} \mathrm{wt}$ construct, we created constructs termed $p \alpha-\mathrm{iE}_{\mathrm{k}}-\mathrm{mt \kappa B}$ and $\mathrm{p} \alpha-\mathrm{iE}_{\mathrm{K}}-$ mtAP-1, respectively (Fig. 2A). These constructs were introduced individually into human nasopharyngeal carcinoma cell lines to test the activity of $\mathrm{iE}_{\kappa}$. As shown in Fig. $2 \mathrm{~B}$, mutation of the NF- $\mathrm{KB}$ or the AP-1 motif significantly decreased LMP1-increased $\mathrm{iE}_{\mathrm{\kappa}}$ activity $(\mathrm{p}<0.01$ and $\mathrm{p}<$ 0.05 , respectively). In addition, the magnitude of the 

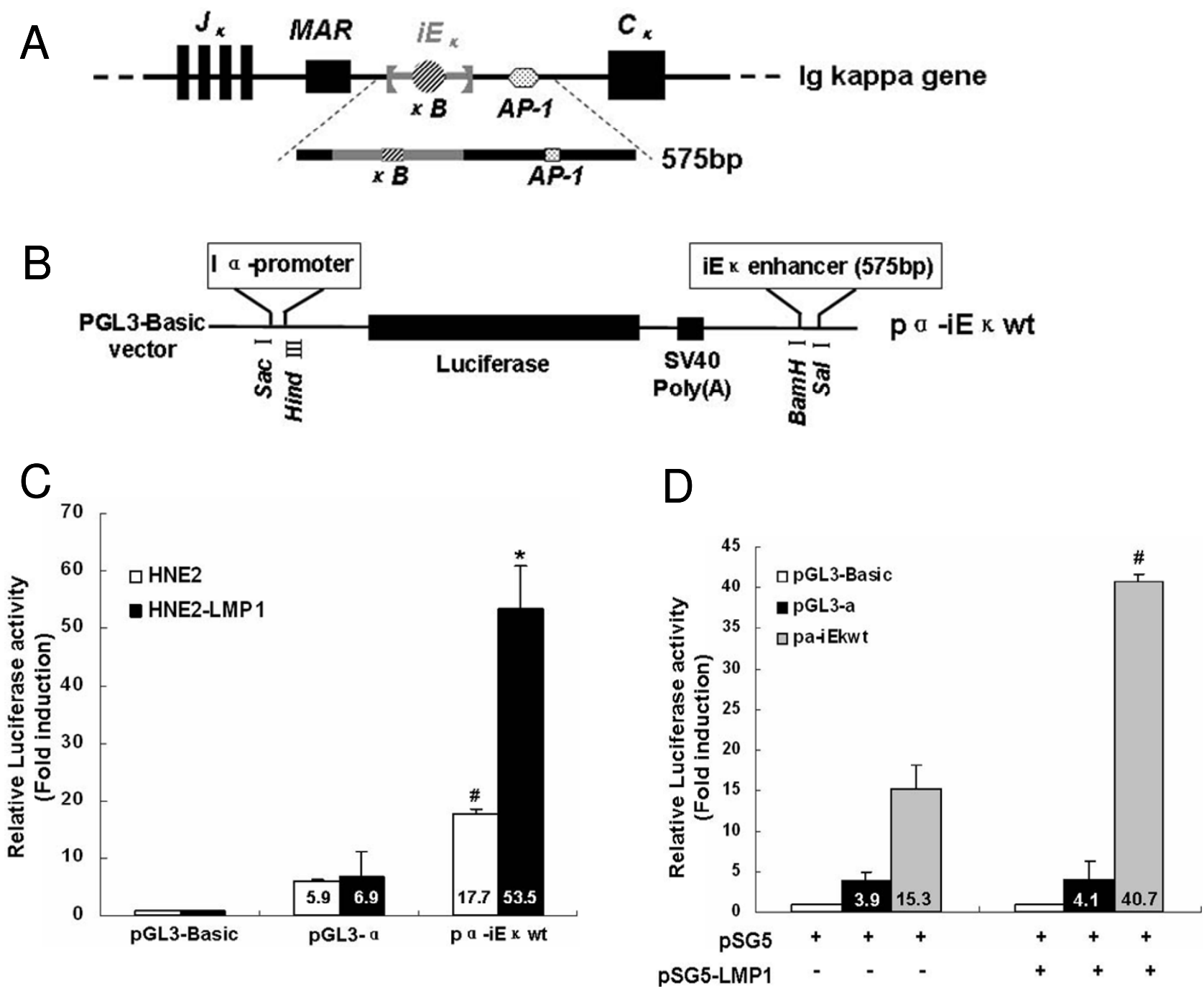

Figure I

Activation of the $\mathrm{iE}_{\kappa}$ enhancer and enhancement of the $\mathrm{iE}_{\kappa}$ activity by LMPI in human nasopharyngeal carcinoma cells. (A) Schematic diagram of human $\mathrm{iE}_{\mathrm{K}}$-containing $\mathrm{DNA}$ fragment used in these experiments. Position of the $i \mathrm{E}_{\mathrm{K}}$, the $\mathrm{NF}-\kappa \mathrm{B}$ and the AP-I binding sites were shown. For simplicity, other protein-binding sites in the $\mathrm{i}_{\kappa}$ were not shown. (B) Insertion sites for the definite DNA fragment into the PGL3- $\alpha$ plasmid which contains the human immunoglobulin l $\alpha$ promoter and the firefly luciferase reporter gene. $(C)$ Comparison of the activities of $\mathrm{iE}_{\mathrm{k}}$ in human nasopharyngeal carcinoma cell lines. Transient transfected the $p \alpha-\mathrm{i}_{\mathrm{K}}$ wt construct, $\mathrm{pGL3}-\alpha$ or $\mathrm{pGL3}-$ Basic vector into HNE2 and HNE2-LMPI cells and luciferase reporter assays were performed as described in Materials and methods. The relative luciferase activity normalized to the value of the internal control plasmid PRL-SV40 activity. Results were expressed as fold induction of pGL3-Basic activity, which was assigned a value of $\mathrm{I}$. The data represent the mean \pm SD of the three independent experiments performed in triplicate. Statistical significance: \# $P<0.01$ vs. $p G L 3-\alpha$-transfected HNE2, $* P<0.01$ vs. $p G L 3-\alpha$-transfected HNE2-LMPI. (D) Transient expression of $\mathrm{LMPI}$ increased the $\mathrm{iE}_{\mathrm{K}}$ activity in nasopharyngeal carcinoma cells. HNE2 cells were co-transfected with $400 \mathrm{ng} /$ well of $p \alpha-i E_{\kappa} w t, p G L 3-\alpha$ or pGL3-Basic vector and $80 \mathrm{ng} /$ well of internal control pRL-SV40 together with $200 \mathrm{ng} / \mathrm{well}$ of PSG5-LMPI or blank expression plasmid pSG5 (total DNA 800 ng). Cells were harvested at $36 \mathrm{~h}$ after transfection and subjected to luciferase analysis. Statistical significance: \# $P<0.01$ vs. PSG5-transfected HNE2.

reduction for $\mathrm{p} \alpha-\mathrm{i} \mathrm{E}_{\mathrm{K}}-\mathrm{mtAP}-1$ was less than that for $\mathrm{p} \alpha-\mathrm{i} \mathrm{E}_{\mathrm{K}}-$ $\mathrm{mt \kappa B}$, implying that of two signaling pathways, NF- $\kappa \mathrm{B}$ pathway might play a leading role in LMP1-augmented $\mathrm{iE}_{\kappa}$ activity in NPC cells. The activity of $\mathrm{iE}_{\kappa}$ in HNE2 cells was moderately decreased by these genetic manipula- tions. Combination this with the results that mutation of either the NF- $\kappa \mathrm{B}$ or the AP-1 motif could not completely abolish the $\mathrm{iE}_{\kappa}$ activity in NPC cells as well as previous reports that several additional functional motifs are located within the $\mathrm{iE}_{\mathrm{\kappa}}[33,34]$, suggested that the variety of 

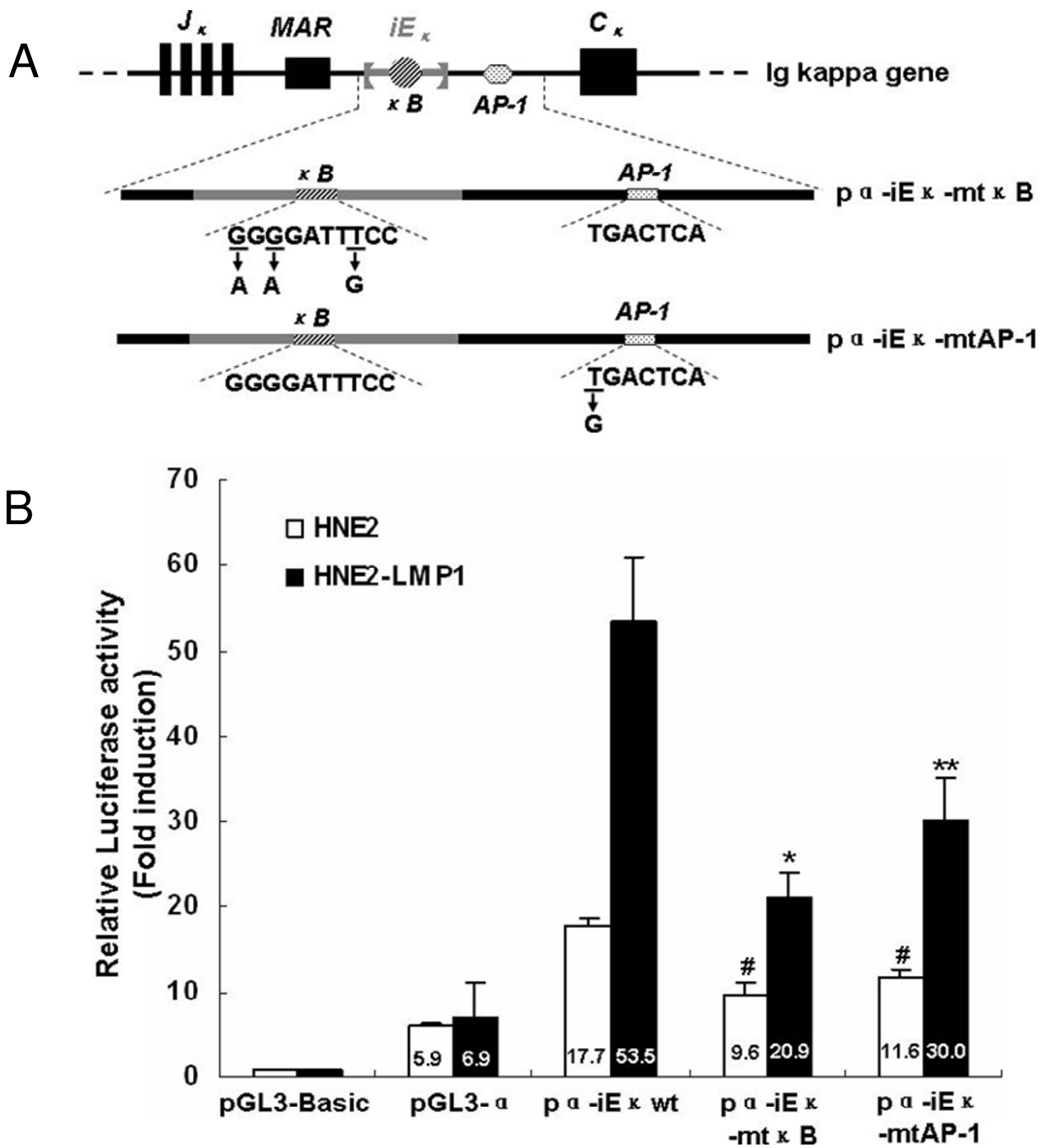

\section{Figure 2}

Mutation of NF-KB or AP-I binding site attenuated LMP I-increased EE $_{\kappa}$ activity. (A) Schematic diagram of mutant $\mathrm{iE}_{\kappa}$ constructs were shown. The expansion for NF- $\kappa B$ or AP-I binding site gave its wild-type sequence and the nucleotides replaced by mutations were underlined. Arrows indicated nucleotides introduced by mutations. (B) Comparison of the activities of $\mathrm{iE}_{\kappa}$ in human nasopharyngeal carcinoma cell lines. Transient transfected the constructs carrying wild-type NF- $\kappa B$ and $A P-$ I sequences $\left(p \alpha-i E_{\kappa} w t\right)$, mutant NF- $\kappa B$ sequence $\left(p \alpha-i E_{\kappa}-m t \kappa B\right)$, mutant $A P-I$ sequence ( $\left.\alpha-i E_{\kappa}-m t A P-I\right)$, $p G L 3-\alpha$ or $p G L 3-$ Basic into HNE2 and HNE2-LMPI cells and luciferase reporter assays were performed as described in Materials and methods. The relative luciferase activity normalized to the value of the internal control plasmid PRL-SV40 activity. Results were expressed as fold induction of pGL3-Basic activity, which was assigned a value of I. The data represent the mean \pm SD of the three independent experiments performed in triplicate. Statistical significance: \#P $<0.05 v s$. p $\alpha$-i $E_{\kappa} w t-t r a n s f e c t e d ~ H N E 2$, $* P<$ 0.01 and $* * \mathrm{P}<0.05$ vs. $\mathrm{p} \alpha-\mathrm{iE}_{\mathrm{K}}$ wt-transfected HNE2-LMPI. 
nuclear factors that can bind to the $\mathrm{iE}_{\kappa}$ may result in complex regulatory pathways. Together, the results indicate that both NF- $\mathrm{KB}$ and AP-1 biding sites contribute to the basal and the LMP1-induced $\mathrm{iE}_{\kappa}$ activities in NPC cells.

\section{Abrogation of LMPI-augmented human kappa intron enhancer activity by inhibitors and dominant negative mutants targeting for NF- B and AP-I pathways}

To further confirm both NF- $\kappa$ B and AP-1 sites contributed to LMP1-augmented $\mathrm{iE}_{\kappa}$ activity, we used various specific inhibitors and dominant negative mutants for NF- $\kappa \mathrm{B}$ and AP-1 signaling pathways to block the LMP1-mediated $\mathrm{iE}_{\kappa}$ activation. As shown in Fig. 3A, LMP1-induced $\mathrm{iE}_{\mathrm{\kappa}}$ activity was significantly inhibited by $20 \mu \mathrm{M}$ Bay11-7082 (p < $0.01)$ or $20 \mu \mathrm{M}$ SP600125 ( $<<0.05)$ but not by the DMSO vehicle control. These two compounds also decreased the $\mathrm{iE}_{\mathrm{K}}$ activity in HNE2 cells to a certain extent but did not have statistical difference $(\mathrm{P}>0.05)$, which was consistent with the previous immunoblot results that both compounds have no obvious inhibitory effects on kappa expression in HNE2 cells [1]. It was reported Bay11-7082 reduces only the constitutive but not the inducible activity of NF-кB [35]. We speculated SP600125 might reduce only the constitutive but not the inducible activity of JNK as did Bay11-7082, which might explain why both of them were not capable of decreasing the $\mathrm{iE}_{\kappa}$ activity and kappa expression in HNE2 cells. Moreover, 20 $\mu \mathrm{M}$ Bay11-7082 showed more inhibitory effect on the activity of $\mathrm{iE}_{\kappa}$ than $20 \mu \mathrm{M}$ SP600125. We have found that the amount of kappa light chain in HNE2-LMP1DNMI $\mathrm{B} \alpha$ and HNE2-LMP1-TAM67 cell lines is significantly lower than that in their parental cell line HNE2LMP1 [1]. We therefore investigated whether the downregulation of kappa chain was correlated with the $\mathrm{iE}_{\mathrm{K}}$ activity in the same cell lines. The results showed that the augmenting effect of $\mathrm{iE}_{\kappa}$ activity by LMP1 was obviously attenuated when DNMI $\mathrm{B} \alpha$ and TAM67 were stably tranfected into HNE2-LMP1 cells (Fig. 3B). Transient co-transfection of DNMI $\mathrm{B} \alpha$ or TAM67 with LMP1 into HNE2 cells significantly declined the LMP1-upregulated $\mathrm{iE}_{\kappa}$ activity (Fig. 3C). Together, these results again indicate that both NF- $\kappa \mathrm{B}$ and AP-1 pathways play roles in the LMP1-upregulated $\mathrm{iE}_{\mathrm{K}}$ activity in NPC cells.

\section{LMPI promotes $p 52$ and $p 65$ binding to the NF- B motif} as well as c-Jun and c-Fos binding to the $A P-I$ motif in vitro We demonstrated that the activity of $\mathrm{iE}_{\kappa}$ was upregulated in HNE2-LMP1 cells and the activity of $\mathrm{iE}_{\kappa}$ in the experimental NPC cell lines was consistent with their kappa chain expression patterns. To further investigate whether there was any correlation between our reporter expression and transcription factor binding activities of the DNA fragments covering the NF- $\kappa \mathrm{B}$ and AP-1 motifs from the $\mathrm{iE}_{\mathrm{K}}$-containing $\mathrm{J}_{\mathrm{K}}-\mathrm{C}_{\mathrm{K}}$ region of human kappa gene, we performed electrophoresis mobility shift assays to examine the protein complexes formed with $\kappa \mathrm{NF}-\kappa \mathrm{B}$ and $\kappa \mathrm{AP}-1$ motifs at NPC cell lines. Biotin-labeled double-stranded $\kappa \mathrm{NF}-\kappa \mathrm{B}$ and $\kappa \mathrm{AP}-1$ oligonucleotide probes as well as equal amounts of nuclear extracts from HNE2, HNE2LMP1, HNE2-LMP1-DNMIкB $\alpha$, HNE2-LMP1-TAM67, Bay11-7082-treated HNE2-LMP1 and SP600125-treated HNE2-LMP1 cells were used. As Fig. 4A shown, LMP1 caused a much stronger NF- $\kappa \mathrm{B}$ DNA binding activity in HNE2-LMP1 cells than that in HNE2 cells (lane 2 vs. lane $3)$. The nuclear lysates isolated from HNE2-LMP1$\mathrm{DNMI} \kappa \mathrm{B} \alpha$ cells induced a weaker electromobility shift band than that from their parental cells HNE2-LMP1 (lane $3 v$ s. lane 4 ). We also found that the induction of NF- $\kappa$ B DNA binding activity by LMP1 was clearly inhibited by $20 \mu \mathrm{M}$ Bay11-7082 (lane $3 v$ s. lane 5). To demonstrate the specificity of these interactions, competitive binding assays were performed. Excess unlabeled doublestranded $\kappa N F-\kappa B$ oligonucleotide was included in the binding assay mixtures. A 200-fold excess of unlabeled oligonucleotide could completely compete for the protein binding seen with the HNE2-LMP1 cell extracts (lane 6). However, the same excess of the unlabeled mutant $\kappa \mathrm{NF}$ $\kappa \mathrm{B}$ oligonucleotide (lane 7 ) or oligonucleotide containing the KAP-1 binding motif (lane 8 ) did not compete for the complex. In addition, the nuclear lysates isolated from these cell lines did not induce an electromobility shift when biotin-labeled $\kappa \mathrm{NF}-\kappa \mathrm{B}$ mutant-type oligonucleotide was introduced (Fig. 4B). These implied that the complex formed with extracts was specific to the sequence of the $\kappa N F-\kappa B$ oligonucleotide. To characterize the composition of the DNA-bound NF- $\kappa \mathrm{B}$ complex, we performed superEMSA with antibodies specific for NF- $\kappa \mathrm{B}$ family members p50, p52, p65, c-Rel and RelB to analyze the nuclear extracts of HNE2-LMP1 cells. As shown in Fig. 4C, the addition of p50, c-Rel and RelB antibody did not influence the mobility or intensity of the NF- $\kappa \mathrm{B}$ binding complex (lanes 4, 7 and 8), whereas the addition of antibodies for p52 and p 65 resulted in a significant diminishment or supershift of the specific complex (lanes 5 and 6). A control IgG antibody failed to attenuate the shift or elicit a supershift (lane 9). The results indicate the presence of p52 and p65 proteins in the complex with the kappa NF$\kappa \mathrm{B}$ binding site. We further tested the effect of LMP1 on p65 and p52 expression. Though no obvious difference of p65 level in HNE2 and HNE2-LMP1 cells (Fig. 4D), by separating cytoplasmic and nuclear fractions, we found LMP1 led to p65 nuclear translocation (Fig. 4E). We also found LMP1 induced the processing of p100 to p52 (Fig. $4 \mathrm{~F}$ ) and the nuclear translocation of p52 (Fig. 4G). Efficient separation of the cytoplasmic and nuclear fractions was demonstrated by western blotting for cytoplasmic ( $\alpha$ tubulin) and nuclear (nucleolin) markers [36,37]. We next examined whether the interaction of p 65 and p52 could be observed at endogenous levels. For this purpose, co-immunoprecipitation (co-IP) experiments were per- 


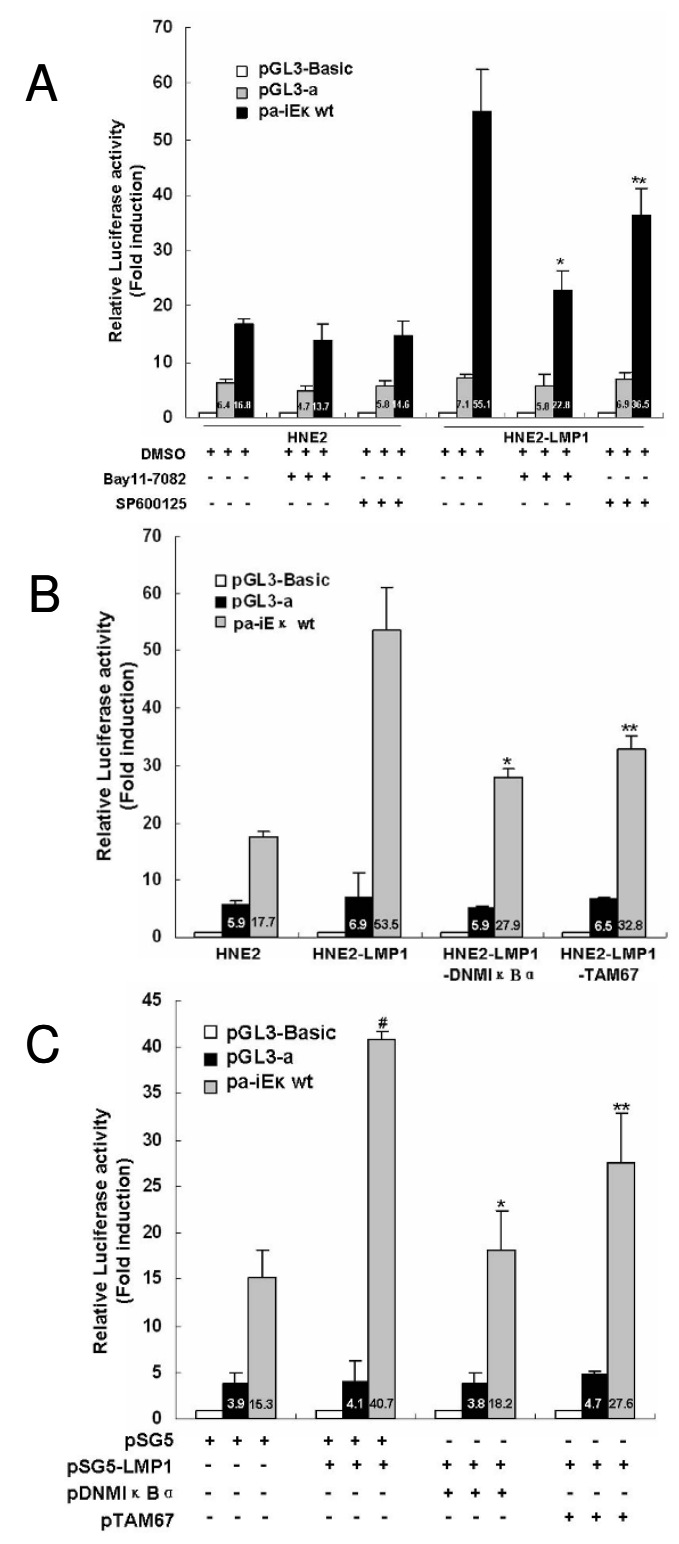

Figure 3

Inhibitors and dominant negative mutants targeting for NF- $\kappa$ B and AP-I pathways attenuated LMP I-augmented human $\mathrm{iE}_{\kappa}$ activities. (A) Bayl I-7082 and SP600I 25 inhibited the activities of $\mathrm{iE}_{\mathrm{K}}$ induced by stable expression LMPI. HNE2 and HNE2-LMPI cells were transfected with $p \alpha-i E_{k} w t, p G L 3-\alpha$ or $p G L 3-B a s i c$ vector, and $p R L-S V 40$ as an internal control for transfection efficiency. $24 \mathrm{hr}$ after transfection, cells were treated with Bay I I-7082 (20 $\mu$ M), SP600I25 (20 $\mu$ M) or $0.1 \%$ DMSO for $12 \mathrm{hr}$. Cells were harvested at $36 \mathrm{~h}$ after transfection and subjected to the luciferase assay. Statistical significance: $* \mathrm{P}<0.01$ and $* * \mathrm{P}<0.05$ vs. HNE2-LMPI vehicle control. (B) Stable expression DNMI $\mathrm{B} \alpha$ and TAM67 inhibited the

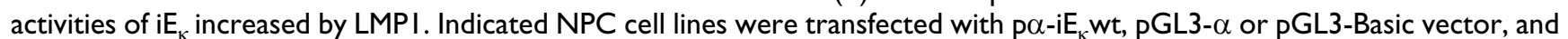
PRL-SV40 as an internal control for transfection efficiency. Cells were harvested at $36 \mathrm{~h}$ after transfection and subjected to the luciferase assay. Statistical significance: $* P<0.0$ I and $* * P<0.05$ vs. HNE2-LMPI control. (C) Both DNMI $\mathrm{PB} \alpha$ and TAM67 inhibited the activities of $\mathrm{iE}_{\mathrm{K}}$ induced by transient expression LMPI. HNE2 cells were co-transfected with $400 \mathrm{ng} / \mathrm{well}$ of $p \alpha-$ $\mathrm{iE}_{\kappa} \mathrm{wt}, \mathrm{pGL3}-\alpha$ or pGL3-Basic vector and $80 \mathrm{ng} /$ well of internal control pRL-SV40 together with $200 \mathrm{ng} /$ well of pSG5-LMPI, pDNMI $\mathrm{B} \alpha$ or $\mathrm{PTAM} 67$ expression plasmid. The total amount of DNA ( $800 \mathrm{ng})$ was kept constant by addition of blank expression plasmid PSG5 necessary to normalize the amount of DNA transfected. Cells were harvested at $36 \mathrm{~h}$ after transfection and subjected to the luciferase assay. Statistical significance: \# $\mathrm{P}<0.01$ vs. PSG5-transfected HNE2, $* \mathrm{P}<0.0 \mathrm{I}$ and $* * \mathrm{P}<$ 0.05 vs. PSG5-LMPI-transfected HNE2. 
formed with non-denatured nuclear extracts from human nasopharyngeal carcinoma cell line HNE2-LMP1. As shown in Fig. 5, the p65 antibody could specifically coprecipitate endogenous p52 (Fig. 5, upper panel, compare lane 2 using p65 with lane 3 using control IgG antibody). Endogenous p 65 could also be detected in a reverse co-IP experiment using p52 antibody in the IP step (Fig. 5, lower panel, lane 5). IgG was used as a negative control in the IP reaction. The protein input was shown as indicated. These results reveal a heterodimerization between p 65 and p52, which is likely relevant to kappa light chain expression upregulated by LMP1 in NPC cells.

Similarly, LMP1 increased the formation of AP-1 DNA binding complex (Fig. 6A, lane 2 vs. lane 3). The nuclear lysates isolated from HNE2-LMP1-TAM67 cells induced a weaker electromobility shift band than that from their parent cells HNE2-LMP1 (Fig. 6A, lane $3 v$ s. lane 4). The induction of AP-1 DNA binding activity by LMP1 was clearly inhibited by $20 \mu \mathrm{M}$ SP600125 (Fig. 6A, lane $3 v$ s. lane 5). Protein binding to the KAP-1 probe was completely abrogated by a 200 -fold excess of unlabeled wildtype КAP-1 probe (Fig. 6A, lane 6), but not by the same excess of unlabeled oligonucleotide probe containing mutation in the KAP-1 sequence (Fig. 6A, lane 7) and unlabeled $\kappa$ NF- $\kappa \mathrm{B}$ probe (Fig. $6 \mathrm{~A}$, lane 8 ). On the other hand, the nuclear lysates isolated from these cells did not induce an electromobility shift when biotin-labeled $\mathrm{AP}$ 1 mutant-type oligonucleotide was introduced (Fig. 6B). These implied that the complex formed with extracts was specific to the sequence of the KAP-1 oligonucleotide. To gain more insight into the composition of the protein complex bound to the human KAP-1 motif, we performed supershift analysis using nuclear extracts from HNE2LMP1 cells. The addition of c-Jun antibody into the nuclear extracts of HNE2-LMP1 cells supershifted the complex (Fig. 6C, lane 3). Exposure of nuclear extracts from HNE2-LMP1 cells to c-Fos antibody and subsequent precipitation of the formed immune complex reduced the intensity of protein-DNA interaction by approximately 50\% (Fig. 6C, lane 4). The super-EMSA results suggest that c-Jun and c-Fos are components of the complex bound to the human kappa AP-1 motif. Moreover, we found LMP1 could significantly upregulate JNK phosphorylation ([1] and Fig. 6D) and simultaneously upregulate the phosphorylation level of c-Jun at Ser63 and Ser73 in the nucleus (Fig. 6D). However, expression of c-Jun and c-Fos were essentially equal in HNE2 and HNE2-LMP1 cells ([1] and Fig. 6E). These results implied that LMP1-increased JNK activation led to the increased phosphorylation of c-Jun at Ser63 and Ser73, which might promote the JNK substrate c-Jun heterodimerize with c-Fos to form the AP-1 complex. To examine if c-Jun endogenously interacts with cFos, we performed co-IP experiments. As shown in Fig. 7,
co-IP performed with anti-c-Jun antibody showed the coprecipitation with c-Fos from non-denatured nuclear extracts of HNE2-LMP1 cells (Fig. 7, upper panel, lane 2). Likewise, co-IP using anti-c-Fos antibody displayed c-Jun protein (Fig. 7, lower panel, lane 5). IgG was applied as a negative control in the IP reaction. The protein input was shown as indicated. These data show that the endogenous c-Jun and c-Fos associate in vivo.

Taken together, the results indicate that $\mathrm{p} 52 / \mathrm{p} 65$ and cJun/c-Fos heterodimers can bind to the $\mathrm{\kappa B}$ and the AP-1 site of human Ig kappa gene in vitro, respectively, which may be the key events in upregulating the activity of $\mathrm{iE}_{\mathrm{K}}$ by LMP1 in NPC cells.

\section{LMPI promotes $p 52 / p 65$ binding to the NF- B motif as well as c-Jun/c-Fos binding to the AP-I motif in vivo}

To better understand p52/p65 and c-Jun/c-Fos heterodimers in the regulation of the human $\mathrm{iE}_{\kappa}$ in vivo, we analyzed the fragments that span the NF- $\mathrm{KB}$ and the AP-1 binding regions within and downstream the $\mathrm{iE}_{\mathrm{k}}$ using a chromatin immunoprecipitation assay (ChIP), respectively. The HNE2-LMP1 cells were treated with $1 \%$ formaldehyde to cross-link proteins to chromatin and the cross-linked chromatin was then sheared to fragments of $\sim 500 \mathrm{bp}$ in length via sonication (Fig. 8A). The sheared cross-linked chromatin was subsequently subjected to immunoprecipitation reactions using antibodies specific for the NF- $\mathrm{KB}$ family members p50, p52, p65, c-Rel and RelB as well as AP-1 family members c-Jun and c-Fos. An anti-IgG antibody was used as a nonspecific control. The precipitated chromatin DNA was then purified and amplified by PCR using primers specific for the NF- $\mathrm{KB}$ or the AP-1 binding site of Ig kappa gene. As shown in Fig. 8B, the primers for the human $\mathrm{iE}_{\mathrm{K}}$ region containing the NF- $\mathrm{KB}$ binding site produced 159-bp amplicons that could be observed with the positive control (input chromatin) and when the chromatin was precipitated with antibodies specific for p52 and p65. Use of the p50, c-Rel, RelB antibody showed no positive signal and no amplification was observed with three negative controls (no chromatin, no antibody, and IgG). Another set of primers was used to analyze for in vivo AP-1 binding to the region located downstream the $\mathrm{iE}_{\mathrm{k}}$ encompassing the AP-1 site. As shown in Fig. 8C, the AP1 family members c-Jun and c-Fos antibodies could precipitate sequences that could be PCR-amplified and produced 188-bp amplicons using this second set of primers. Therefore, the ChIP results indicate that p52/p65 and cJun/c-Fos transcription factors can exert its regulatory function through direct binding to the human $\mathrm{iE}_{\mathrm{k}}$ enhancer and the adjacent sequence. 


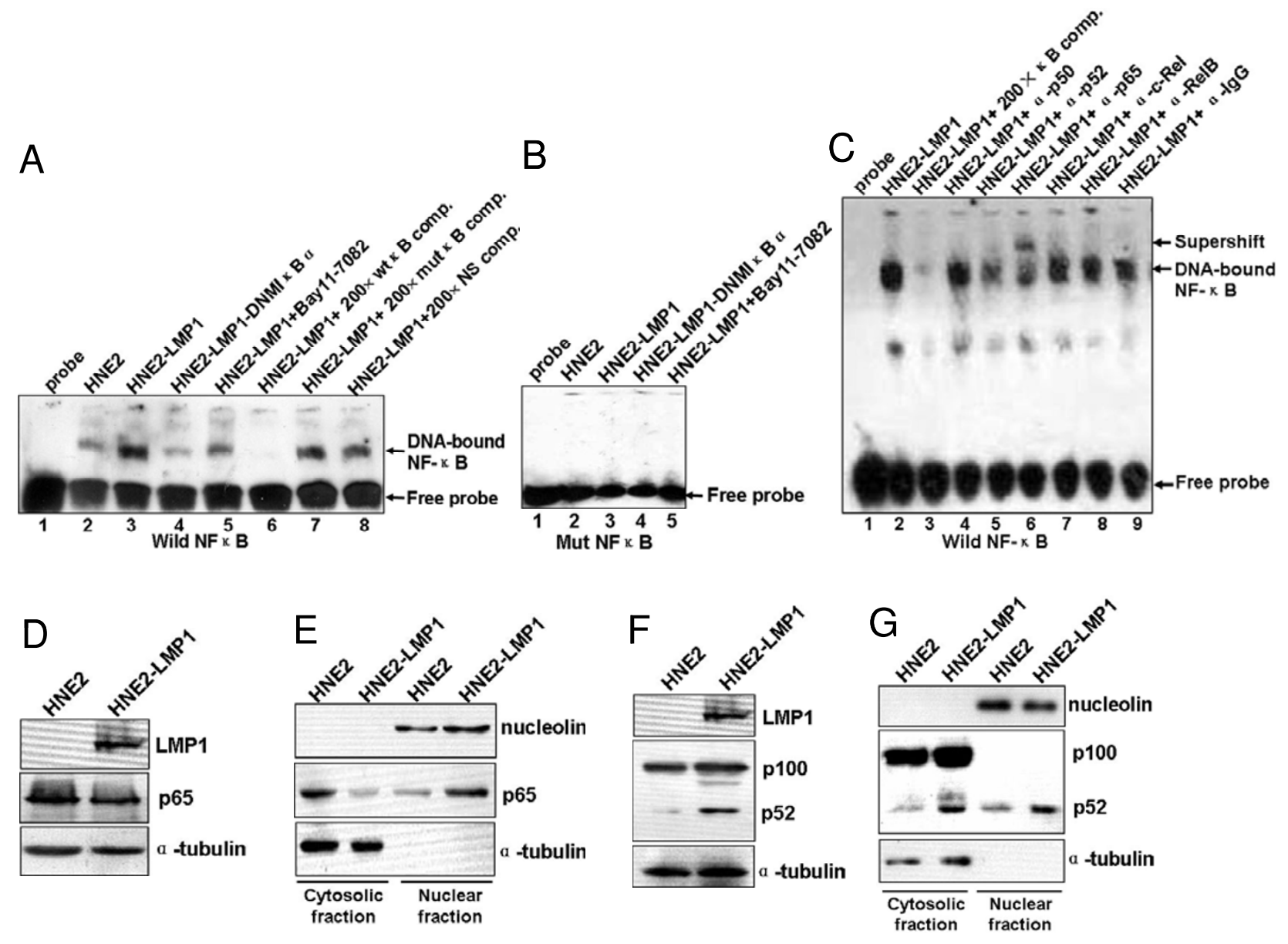

Figure 4

LMP I increased the binding ability of p52 and p65 transcription factors to $\kappa$ NF- $\kappa$ B motif in vitro. (A) Biotinlabeled wild-type $\kappa$ NF- $\kappa B$ oligonucleotide probe was incubated with nuclear extracts of HNE2, HNE2-LMPI, HNE2-LMPIDNMI $\mathrm{B} \alpha$ and Bayl I-7082-treated HNE2-LMPI (20 $\mu \mathrm{M}$ for $12 \mathrm{hr})$ NPC cells in the presence of a 200-fold excess of unlabeled wild-type $\kappa$ NF- $\kappa B$ (lane 6), unlabeled mutant $\kappa$ NF- $\kappa B$ oligonucleotides (designated as mut $\kappa B$, lane 7) or noncompetitive unlabeled $\kappa$ AP-I oligonucleotide (NS, lane 8), and then NF-KB DNA binding activities were examined by EMSA. (B) Biotin-labeled mutant $\kappa$ NF- $\kappa B$ oligonucleotide probe was incubated with nuclear extracts of indicated NPC cell lines, and then NF- $\kappa B$ DNA binding activities were examined by EMSA. (C) $10 \mu \mathrm{g}$ of HNE2-LMPI nuclear extracts were preincubated with biotin-labeled $\kappa N F-\kappa B$ oligonucleotide probe in the absence (lane 2) or presence of antibodies directed against different NF- $\kappa B$ subunits $p 50$, p52, p65, c-Rel, RelB or control antibody ( $\lg G$ ) (indicated above each lane) and then supershift assays were performed. (D, E) Expression and subcelluar distribution of p65 in HNE2 and HNE2-LMPI cells. Whole cell lysates, cytoplasmic and nuclear fractions were prepared and expression of p 65 was estimated by western blotting. Cytosolic protein $\alpha$-tubulin and nuclear protein nucleolin were detected as protein loading controls. (F, G) Expression and subcelluar distribution of p52 in HNE2 and HNE2LMPI cells. Whole cell lysates, cytoplasmic and nuclear fractions were prepared and expression of p52 was estimated by western blotting. Cytosolic protein $\alpha$-tubulin and nuclear protein nucleolin were detected as protein loading controls.

\section{Discussion}

In this article, we showed that the aberrant expression of Ig kappa light chain in NPC cells. Recent studies have demonstrated that the expression of Igs is widespread in epithelial cancers from many organs and includes basically all kinds of isotypes. Among heavy chains, $\alpha$ chain for IgA and $\gamma$ chain for IgG are the mostly identified; but in light chain, only $\kappa$ chain but not $\lambda$ chain is confirmed. Moreover, several studies indicated that tumor-derived Igs have certain biological functions. Qiu et al [5] found induction of cancer cell apoptosis and inhibition of cancer growth by blocking tumor-derived IgG, whose light chain is kappa, using either antisense oligodeoxynucleotide or anti-human IgG, thus confirming that IgG 


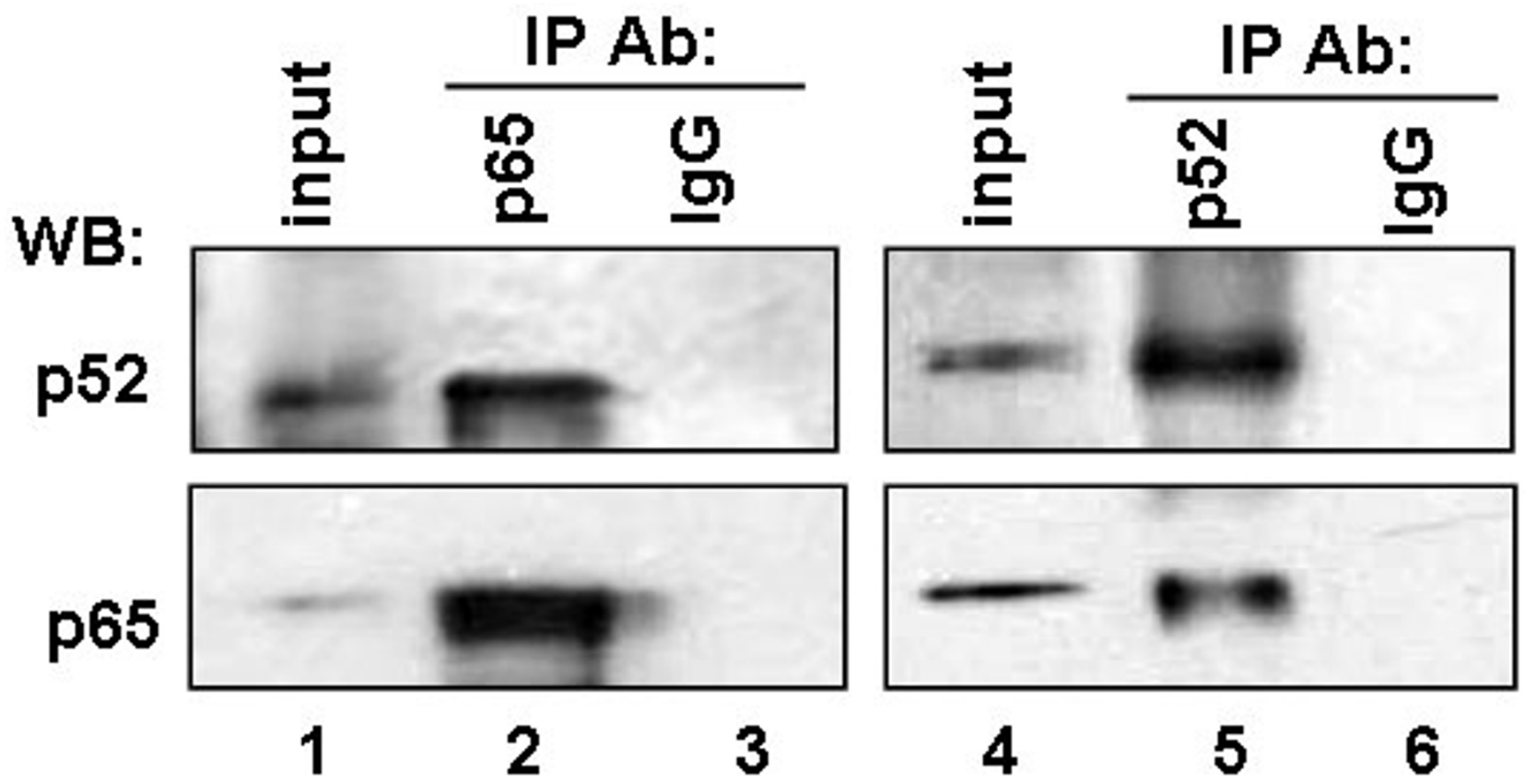

Figure 5

Co-IP of endogenous p65 and p52. Non-denatured nuclear extracts prepared from HNE2-LMPI cells were immunoprecipitated with anti-p65, anti-p52 or control lgG antibody. The immune complexes and the input (I0\% of the nuclear extracts used in the immunoprecipitation step) were analyzed by immunoblotting with antibody specific to p52 (upper panel, lanes I-3) or p65 (lower panel, lanes 4-6). The same membrane was stripped and reprobed to detect p65 (lower panel, lanes I-3) or p52 (upper panel, lanes 4-6).

secreted by epithelial cancers has some unidentified capacity to promote the growth and survival of tumor cells. We also found that blockade of cancer-derived Ig alpha suppresses the growth and viability of cancer cells. Furthermore, we have demonstrated that cancer-derived Ig alpha promotes the malignant proliferation ability of cancer cells and increases the access percentage of $S$ phase from the early mitosis of synchronized cancer cells [38]. These findings support the important role of cancerderived Ig as a growth factor of cancer cells. In addition, By in situ hybridization to analyze kappa constant region mRNA in different stages of cervical tissue samples, we found that the expression of kappa constant region mRNA is markedly increased in uterine cervical epithelia with dysplasia and carcinoma, as compared with cervicitis, thus suggesting a closely associated of kappa light chain expression with cell malignancy and is associated with increasing tumor grades [10]. Recently, we analyzed the ADCC immuno-activity of Ig derived from cancer cells and found that cancer-derived Ig is capable of reacting with FcR of monocytes and NK cells by its Fc region as does normal Ig, and to accomplish ADCC with effector cells (unpublished data). Based on these findings, it may be hypothesized that cancer-derived Ig could compete with B cell-derived Ig for the FCR on effector cells, thus inhibits ADCC and favors tumor immune escape. The potential biological functions of the tumor-derived Igs and the finding that nonlymphoid cells expressing Igs reported by different research groups revealed that this phenomenon is not a happenchance. However, the mechanisms underlying the expression of Igs in nonlymphoid cells are still unknown. In present study, we focus mainly on exploring the possible mechanisms by which nonlymphoid cells expressed Ig kappa and found that in Igкexpressing NPC cells, kappa intron enhancer is activated. The activity of $\mathrm{iE}_{\mathrm{k}}$ can be further activated by LMP1-stimulated NF- $\mathrm{BB}$ and AP-1 aberrant activation. It could be concluded that LMP1 stimulates transcription factors NF$\kappa \mathrm{B}$ and $\mathrm{AP}-1$ binding to the corresponding site in kappa gene via NF- $\mathrm{kB}$, JNK/MAPK signal pathways and finally upregulates kappa light chain induction. Such mechanisms would explain, at least in part, LMP1-positive human epithelial cancer cells produce immunoglobulins.

The activation of kappa enhancers, whose function is mediated by proteins binding to the enhancers, is required for Ig kappa gene expression [12,14,15]. We found the $\mathrm{iE}_{\mathrm{K}}$ is active in both LMP1-negative and LMP1positive NPC cells. In LMP1-negative HNE2 cells, the $\mathrm{iE}_{\mathrm{k}}$ activity is relatively low and is in accord with low kappa expression level. LMP1 can further activate the activity of $\mathrm{iE}_{\kappa}$ and contributes to the upregulation of Ig kappa in NPC 

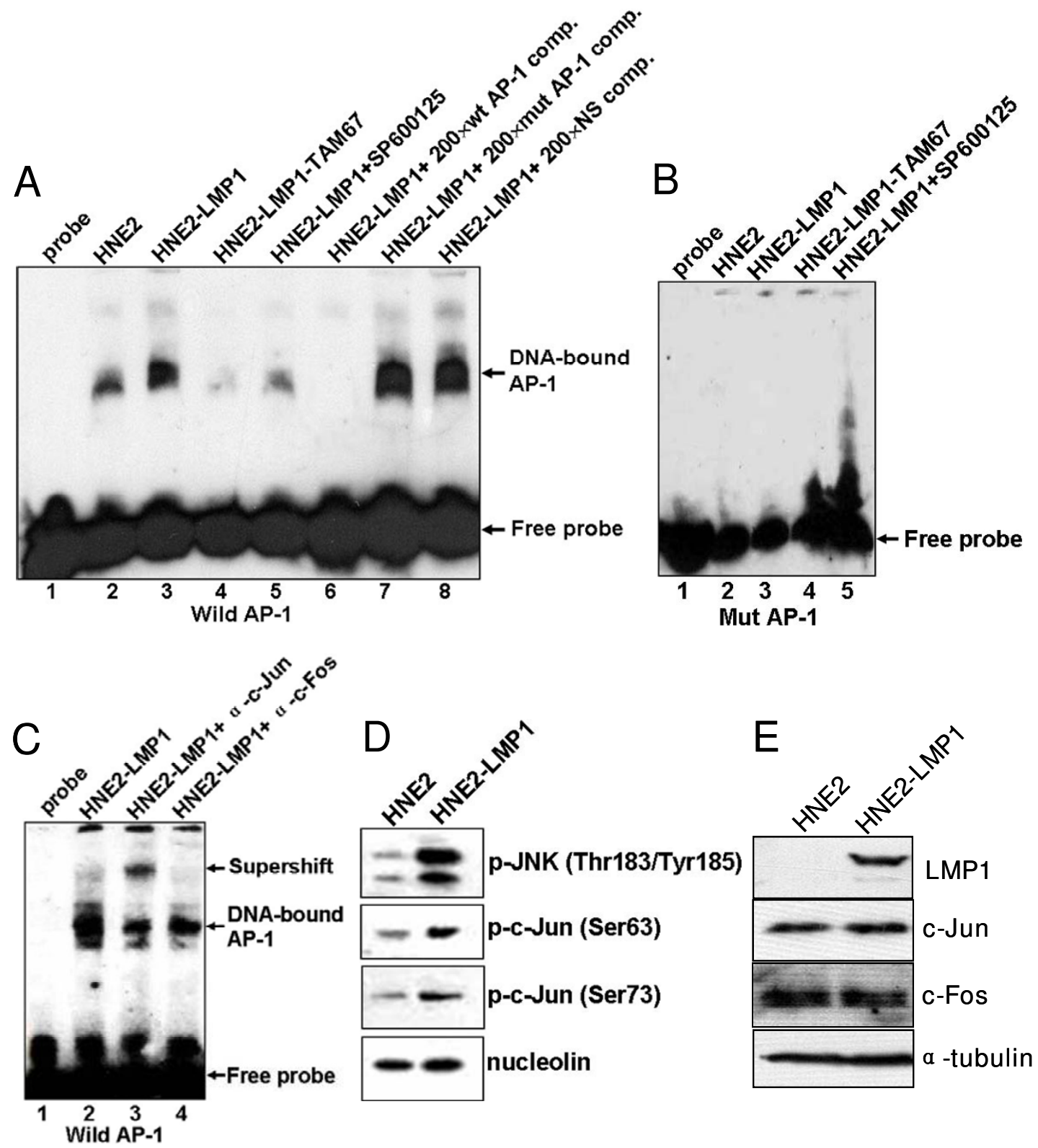

Figure 6

LMPI increased the binding ability of c-Jun and c-Fos transcription factors to $K A P-I$ motif in vitro. (A) Biotinlabeled wild-type $\kappa$ AP-I oligonucleotide probe was incubated with nuclear extracts of HNE2, HNE2-LMPI, HNE2-LMPITAM67 and SP600I25-treated HNE2-LMPI $(20 \mu \mathrm{M}$ for $12 \mathrm{hr})$ NPC cells in the presence of a 200-fold excess of unlabeled wild-type KAP-I (lane 6), unlabeled mutant KAP-I oligonucleotides (designated as mutAP-I, lane 7) or noncompetitive unlabeled $\kappa$ NF- $\kappa$ B oligonucleotide (NS, lane 8 ), and then AP-I DNA binding activities were examined by EMSA. (B) Biotin-labeled mutant KAP-I oligonucleotide probe was incubated with nuclear extracts of indicated the NPC cell lines, and then AP-I DNA binding activities were examined by EMSA. (C) $10 \mu \mathrm{g}$ of HNE2-LMPI nuclear extracts were preincubated with biotin-labeled KAP-I oligonucleotide probe in the absence (lane 2) or presence of antisera directed against c-Jun (lane 3), c-Fos (lane 4) and then supershift assays were performed. (D) Phosphorylation levels of JNK and c-Jun in HNE2 and HNE2-LMPI cells. The nuclear extracts were prepared and analyzed with phospho-JNK (Thr I83/Tyr I85), phospho-c-Jun (Ser63) and phospho-c-Jun (Ser73) antibodies, respectively. Nucleolin was acted as a nuclear protein loading control. (E) Expression of c-Jun and c-Fos in HNE2 and HNE2-LMPI cells. Whole cell lysates were prepared and expression of c-Jun and c-Fos was estimated by Western blotting. $\alpha$-tubulin was detected as a protein loading control. 
cells. Our results indicated that mutant of either NF-kB or AP-1 biding site did not completely abolish the basal and LMP1-induced $\mathrm{iE}_{\mathrm{\kappa}}$ activities (Fig. $2 \mathrm{~B}$ ). In addition to NF$\kappa \mathrm{B}$ and AP-1 motifs to modulate the enhancer's activity, other positive regulatory elements have been identified within the $\mathrm{iE}_{\kappa^{\prime}}$ including $\mathrm{\kappa A}$ and E-box motifs, these sequences could potentially regulate the activity of $\mathrm{iE}_{\mathrm{k}}$ $[33,34]$. Therefore, other transcription factors bind to kappa gene through various signaling pathways to regulate kappa expression in NPC cells can not be excluded at this time.

In $B$ cells, functional analyses of motifs within $\mathrm{iE}_{\kappa}$ performed using isolated enhancers to activate reporter genes in transfection assays have shown that B cell-specific activity of $\mathrm{iE}_{\kappa}$ depends substantially on the $\kappa \mathrm{B}$ element [39]. Moreover, mutations of E-box motifs have variable and weaker effects on transcription compared to mutation of the $\kappa \mathrm{B}$ site [16]. These observations indicated NF- $\mathrm{KB}$ acts as the master and commander of kappa gene expression via the $\kappa \mathrm{B}$ motif in $\mathrm{iE}_{\kappa}$ in $\mathrm{B}$ cells. Similarly, our result indicated mutation of the NF- $\mathrm{BB}$ motif displayed a more inhibitory effect on LMP1-increased $\mathrm{iE}_{\kappa}$ activity compared to mutation of the AP-1 site, suggested that of NF- $\mathrm{KB}$ and AP-1 pathways, NF- $\mathrm{KB}$ pathway may play a leading role in LMP1-augmented $\mathrm{iE}_{\mathrm{\kappa}}$ activity in NPC cells.

Transcripition factor NF- $\kappa \mathrm{B}$ comprised of homo- and heterodimers of the p65 (RelA), RelB, c-Rel, p50/p105 (NF-

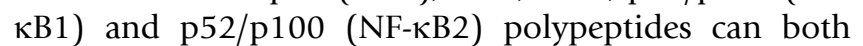

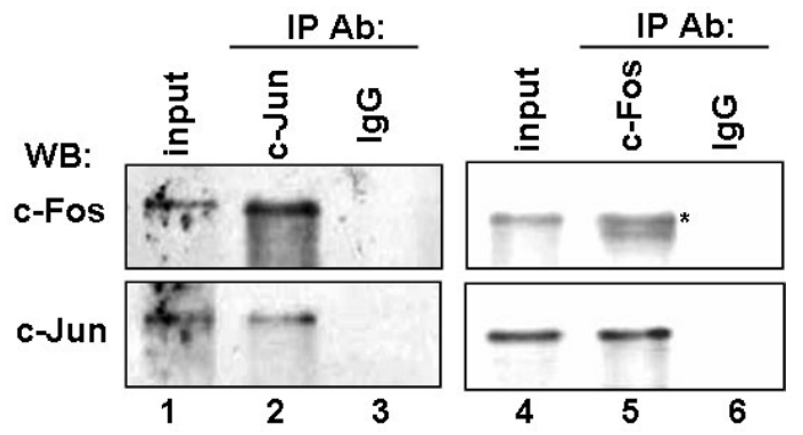

\footnotetext{
Figure 7

Co-IP of endogenous c-Jun and c-Fos. Non-denatured nuclear extracts prepared from HNE2-LMPI cells were immunoprecipitated with anti-c-Jun, anti-c-Fos or control IgG antibody. The immune complexes and the input ( $10 \%$ of the nuclear extracts used in the immunoprecipitation step) were analyzed by immunoblotting with antibody specific to cFos (upper panel, lanes I-3) or c-Jun (lower panel, lanes 4-6). The same membrane was stripped and reprobed to detect cJun (lower panel, lanes I-3) or c-Fos (upper panel, lanes 4-6). Asterisks marked the specific bands recognized by c-Fos antibody.
}

induce and repress gene expression by binding to discrete $\kappa \mathrm{B}$ elements in promoters and enhancers [40]. NF- $\kappa \mathrm{B}$ is found in the cytoplasm of pre- $\mathrm{B}$ cell lines as an inactive complexes associated with an I $\mathrm{B}$ inhibitor, whereas in mature and transformed B cells, NF- $\mathrm{\kappa B}$ is active and localized in the nucleus. NF- $\mathrm{BB}$ DNA binding activity and nuclear relocalization can be activated by a variety of stimuli. In our previous study, IкB $\alpha$ phosphorylation accompanying by I $\kappa \mathrm{B} \alpha$ degradation has been found in NPC cells and LMP1 can further induced I $\mathrm{B} B \alpha$ phosphorylation and degradation [1]. Our results presented here indicated LMP1 increased the released-NF- $\mathrm{KB}$ translocating freely to the nucleus (Fig. 4E) and binding to the $\kappa \mathrm{B}$ motif of $\mathrm{iE}_{\kappa}$ (Fig. 4A, lane 3). We characterized the NF-kB/DNA complex containing p52 and p 65 subunits by Gel Super-shift assay (Fig. 4C, lanes 5 and 6). We also found LMP1 induced the processing of p100 to p52 (Fig. 4F) and the nuclear translocation of p52 (Fig. 4G). Generally, p50/ p65 is considered as a 'classical' heterodimers. p52 forms heterodimers with other NF- $\kappa B$ subunits, such as p 65 and RelB, or as a homodimer has also been found [41]. However, in our experiments, we failed to detect p50, c-Rel and RelB subunits in NF-kB/DNA complex. We also confirmed the interaction of p52 and p65 at endogenous levels by co-IP assay (Fig. 5). Moreover, both p52 and p65 could directly bind to the NF- $\mathrm{\kappa B}$ binding region within the $\mathrm{iE}_{\mathrm{K}}$ enhancer (Fig. 8B). Perkins [42] found that $\mathrm{p} 52 /$ p65 preferentially activates HIV-1 gene expression relative to the p50/p65 heterodimers, which is similar to our results. The results suggest that a heterodimer of p 65 with p52 subunit binding to $\kappa B$ site within the $\mathrm{iE}_{\kappa}$ may play an important role in upregulating the activity of $\mathrm{iE}_{\mathrm{K}}$ and kappa light chain production in HNE2-LMP1 NPC cells.

We reported earlier that NPC cells express activated forms of JNK (pJNK) whether LMP1-negative or LMP1-positive and LMP1 can increase the phosphorylation level of JNK [1]. JNK is one of the kinases that regulated the activation of AP-1 transcription factor. Upon stimulation, this protein kinase enters the nucleus to induce or phosphorylate subunits of AP-1 and the resultant enhanced AP-1 activity can then participate in the regulation of gene expression. The AP-1 transcription factor is a dimeric complex that comprises a group of structurally and functionally related members of the Jun family (c-Jun, JunB and JunD), Fos family (c-Fos, FosB, Fra-1 and Fra-2), ATF (ATFa, ATF-2 and ATF-3) and JDP (JDP-1 and JDP-2) subfamilies, which can bind to AP-1 consensus sequence 5'-TGAG/ CTCA-3' [43]. Different types of AP-1 complexes are functionally distinct and may activate different target genes [44]. By EMSA analysis, we showed that nuclear extracts of both HNE2 and HNE2-LMP1 cells could bind KAP-1 motif and LMP1 was able to increase this binding (Fig. 6A, lanes 2 and 3). Super-EMSA further characterized the protein/DNA complex containing c-Jun and c-Fos transcrip- 


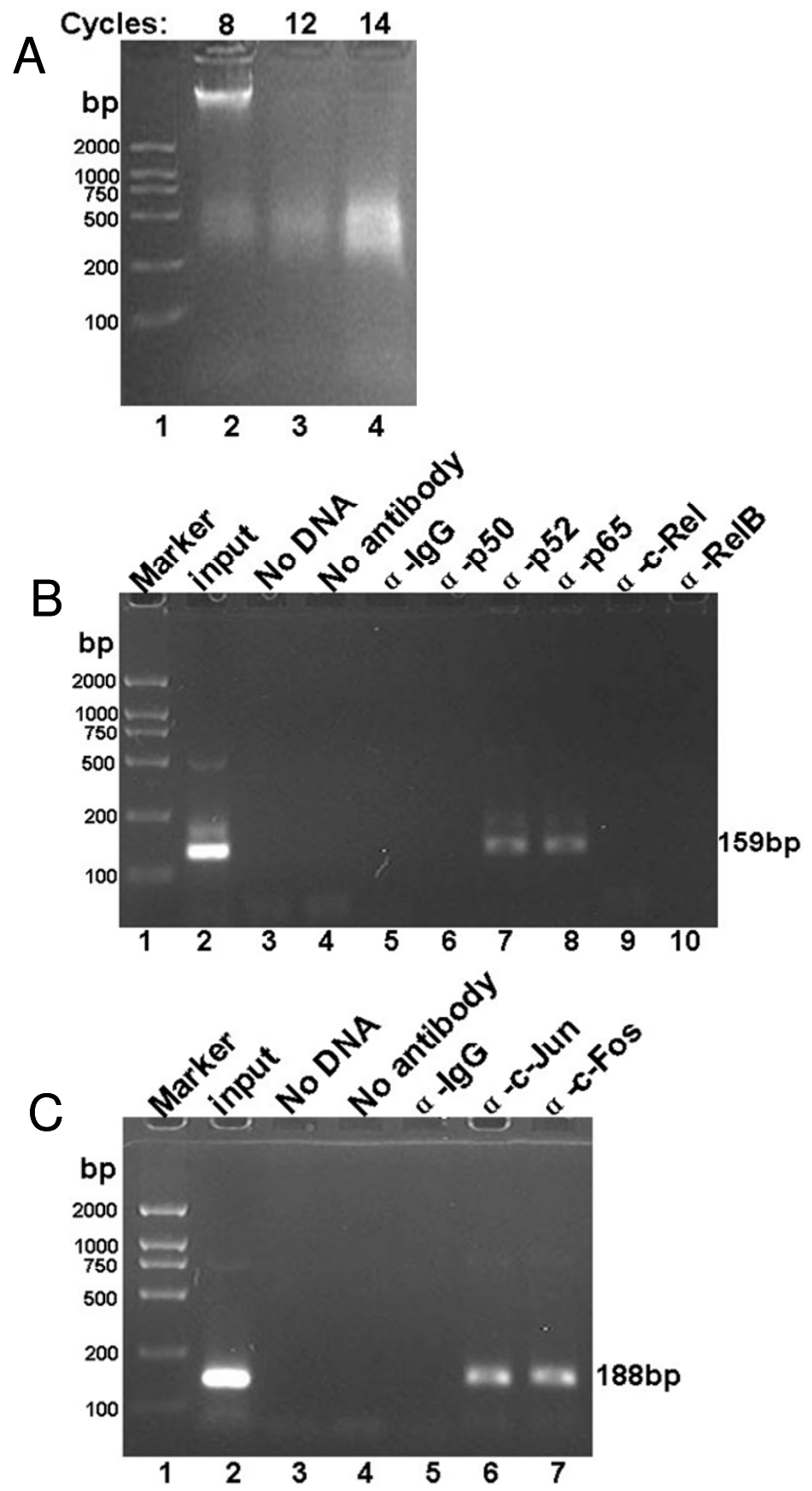

Figure 8

p52/p65 and c-Jun/c-Fos heterodimers interacted with the human Ig kappa intronic enhancer and the adjacent sequence in vivo. (A) DNA sonication. $2 \%$ ethidium bromide-stained agarose gel demonstrated the shearing of chromatin from HNE2-LMPI cells. Average chromatin length was $\sim 500$ bp. (B) ChIP analysis of the NF- $\kappa B$ binding site within the $\mathrm{iE}_{\kappa}$ enhancer in HNE2-LMPI cells. The cross-linked chromatin was precipitated with specific antibodies as indicated. The positive control was represented by the input fraction. Negative controls included a no chromatin sample, no antibody sample, and nonspecific antibody $(\alpha \lg G)$. Precipitated DNA was analyzed by PCR using primers that amplified a I59-bp region that included the NF- $\kappa B$ site. (C) ChIP analysis of the AP-I site located downstream of the iEk enhancer. The PCR primers amplified a I88bp sequence that included the AP-I site. 
tion factors (Fig. 6C). Moreover, our results demonstrated LMP1-induced JNK phosphorylation level coincided with the phosphorylation level of c-Jun at Ser63 and Ser73 in the nucleus (Fig. 6D) and this c-Jun phosphorylation was much closely related to the DNA binding activity of the cJun/c-Fos heterodimer. Similar results that the phosphorylation level of c-Jun (ser63, ser73) is related to the DNA binding activity of c-Jun/JunB heterodimer was reported [23]. Our results suggest that LMP1 can act through activation of JNK, a c-Jun N-terminal kinase needed for AP-1 activation and induce formation of the c-Jun/c-Fos/DNA complex to upregulate the activity of $\mathrm{iE}_{\kappa}$ in NPC cells. We also found stable expression of TAM 67 almost completely blocked LMP1-induced AP-1 DNA binding in HNE2LMP1 cells (Fig. 6A, lane 4). Similar results that stable TAM67 expression completely inhibited MKK6-induced AP-1 binding in MCF-7 cells [45] and an inhibition of nickel-induced AP-1 element binding by TAM67 in human bronchial epithelial cells [46] were recently reported. Although we have demonstrated the heterodimerization of c-Jun and c-Fos (Fig. 7) and this heterodimer can directly bind to the AP-1 site located near the $\mathrm{iE}_{\mathrm{K}}$ enhancer (Fig. 8C), we have used only c-Jun and cFos in this report, therefore, other dimeric forms of AP-1 transcription factor involved in regulating the $\mathrm{iE}_{\mathrm{K}}$ activity in NPC cells can not be excluded at this time.

\section{Conclusion}

The present study presented novel experimental proofs on the mechanisms upregulating the expression of kappa light chain by LMP1 in NPC cells. Since other virusencoded oncoproteins, such as HBX, E6, E7, can also activate many signal pathways including NF- $\mathrm{kB}$ and $\mathrm{AP}-1$ pathways. These oncoproteins might induce immunoglobulin gene expression through the mechanism similar to EBV-LMP1. Our study might offer a new insight into the molecular mechanisms by which nonlymphoid cancer cells expressing immunoglobulin and lay foundations for further studies.

\section{Methods}

\section{Cell lines and cell culture}

HNE2, HNE2-LMP1, HNE2-LMP1-DNMIкB $\alpha$ and HNE2LMP1-TAM67 cell lines used were as previously described [1]. All the cell lines were maintained in RPMI1640 (GIBCO) supplemented with 10\% FBS (GIBCO), 1\% glutamine, and $1 \%$ antibiotics at $37^{\circ} \mathrm{C}$ in humidified atmosphere with $5 \%$ CO2.

\section{Chemicals and cell treatments}

The selective JNK inhibitor SP600125 (Cat No.420119, Calbiochem) and NF-кB inhibitor Bay11-7082 (Cat No.196870, Calbiochem) were prepared as a stock solution of $20 \mathrm{mM}$ in dimethylsulfoxide (DMSO, Sigma). Subconfluent cells were treated with the compound at indicated concentrations for indicated time. Detailed treatment procedures were described in figure legends. The final concentration of DMSO in the culture media was kept less than $0.1 \%$ which had no significant effect on the cell growth.

\section{Plasmid constructs}

The human I $\alpha$ promoter was a 342 bp promoter fragment identical to that used previously [32], obtained by amplification from human HNE2 cells genomic DNA. The sense primer 5'-gagctcctctgtctcggggtctctga-3' used in this reaction was carrying SacI cloning site whereas the antisense primer 5'-aagcttccgtctgtccttagcagagc-3' had Hind III site. Italic nucleotides represent restriction endonuclease recognition sites. This fragment was inserted into the Sac I/ Hind III sites of the pGL3-Basic vector (Promega) and the plasmid was designated as pGL3- $\alpha$.

A $575 \mathrm{bp}$ fragment containing the intact human $\mathrm{iE}_{\mathrm{\kappa}}$ and the AP-l binding site at the 3 ' flank of $\mathrm{iE}_{\mathrm{K}}$ was cloned. Briefly, a 575 bp DNA fragments containing human kappa light chain genomic sequences were amplified from HNE2 cells genomic DNA by PCR using specific primers from the human Ig kappa gene (GenBank accession no. NG 000834): $\quad 5$ '-ggatccctgacttctccctatctgtt-3'(sense), which contains an artificial BamH I site, and 5'-gtcgacccattctgagggctttgc-3'(antisense), which contains an artificial Sal I site. Italic nucleotides represent restriction endonuclease recognition sites. The PCR-amplified fragments were then digested with $\mathrm{BamH} \mathrm{I} / \mathrm{Sal} \mathrm{I}$ and inserted into the corresponding restriction sites of the pGL3- $\alpha$ plasmid described above to generate $\mathrm{p} \alpha-\mathrm{iE}_{\mathrm{\kappa}} \mathrm{wt}$. The PCR products were confirmed by their size, as determined by electrophoresis and by DNA sequencing. The NF- $\mathrm{kB}$ motif and the AP-1 motif mutants (designated as $p \alpha-i E_{\kappa}-m t \kappa B$ and $\mathrm{p} \alpha-\mathrm{iE}_{\mathrm{K}}-\mathrm{mtAP}-1$, respectively) from $\mathrm{p} \alpha-\mathrm{iE}_{\mathrm{K}} \mathrm{wt}$ were generated by PCR based on an overlap extension technique [47]. The primers used for generating mutations were: $5^{\prime}$ ccccagagagagattgccaagaggccacctg-3' and 5'ttggcaatctctctctgggggattc-3' (for NF- $\mathrm{BB}$ site), 5'-gaggctttcctggactcagccgctgcc-3' and 5'-gctgagtccaggaaagcctccg-3' (for AP-1 site). PCR-amplified fragments carrying the desired mutations were then cloned into BamH I/Sal I sites of the pGL3- $\alpha$ plasmid. Bold nucleotides represent sequences of $\kappa N F-\kappa B$ (ggggatttcc) and КAP-1(tgactca) motifs and bold italic nucleotides represent mutated nucleotides. The expected mutations and the integrity of the enhancer were confirmed by automated sequencing using an Applied Biosystems sequencer and software (Foster City, CA).

The pSG5-based expression vector for wild-type LMP1 derived from B95.8 EBV strain was kindly provided by Dr. Izumi (Brigham and Women's Hospital). Expression plasmid of dominant negative mutant of IкB $\alpha$ (DNMIкB $\alpha$ ), which had a deletion of 71 amino acids at the $\mathrm{N}$ terminus 
and was cloned into the multiple cloning sites of pcDNA3, was kindly provided by Dr. Krappmann (MaxDelbruck-center for Molecular Medicine, Berlin, Germany). Expression plasmid of mutant c-Jun (TAM67) was constructed by inserting the TAM67 sequence into the vector $\mathrm{pGem} 3 z$ which contains a human keratin 14 promoter and a human growth hormone segment, was kindly provided by Dr. J. Li (NCI, Frederich, U.S.A.).

\section{Luciferase reporter assays}

The pGL3- $\alpha, p \alpha-\mathrm{iE}_{\mathrm{k}} \mathrm{wt}, \mathrm{p} \alpha-\mathrm{iE}_{\mathrm{\kappa}}-\mathrm{mt \kappa} \mathrm{B}$ and $\mathrm{p} \alpha-\mathrm{iE}_{\mathrm{k}}-\mathrm{mtAP}-1$ luciferase reporter plasmids described above were used in conjunction with the control pGL3-Basic vector (Promega) and the internal control plasmid pRL-SV40 (Promega). Cells were cultured in 24-well plates at a density of $1 \times 10^{5}$ per well overnight and were transfected with Lipofectamine $^{\mathrm{TM}} 2000$ (Invitrogen) as per the manufacturer's instructions. Each transfection contained $800 \mathrm{ng} /$ well of firefly luciferase reporter and $80 \mathrm{ng} /$ well of internal control pRL-SV40 or contained $400 \mathrm{ng} /$ well of firefly luciferase reporter and $80 \mathrm{ng} /$ well of internal control pRLSV40 together with $200 \mathrm{ng} /$ well of each expression plasmid or blank expression plasmid necessary to normalize the amount of DNA transfected. 24 hrs after transfection, cells were either left untreated or treated with $20 \mu \mathrm{M}$ Bay11-7082, $20 \mu \mathrm{M}$ SP600125 or 0.1\% DMSO for 12 hrs. Cells were harvested at $36 \mathrm{~h}$ after transfection and lysates were analyzed for luciferase activity using the Dual Luciferase Reporter assay (Promega) according to the manufacturer's directions with a GloMax ${ }^{\mathrm{TM}}$ Microplate Luminometer (Promega). The luciferase reporter plasmids were co-transfected with pRL-SV40 to correct for variations in transfection efficiency. The relative luciferase activity normalized to the value of pRL-SV40 activity. Results were expressed as fold induction of pGL3-Basic activity, which was assigned a value of 1 . The data represent the mean \pm SD of the three independent experiments performed in triplicate.

\section{Western blot analysis}

Whole cell lysates preparation and western blot analysis were performed according to the method previously described [1]. Nuclear or cytoplasmic extracts were prepared by the use of NE-PER Nuclear and Cytoplasmic Extraction Kit (Cat. No.78833, Pierce) in accordance with the manufacturer's protocol. Protein concentration was determined by BCA Assay Reagent (Cat. No.23228, Pierce). The following antibodies were used for immunodetection with appropriate dilutions: mouse LMP1 monoclonal antibody (CS.1-4, DAKO); p52(sc-298), p65(sc8008), c-Jun(sc-44), c-Fos(sc-52), nucleolin(sc-8031), $\alpha-$ tubulin(sc-5286), goat anti-rabbit IgG-HRP (sc-2004), goat anti-mouse IgG-HRP (sc-2005) and donkey anti-goat IgG-HRP (sc-2020) (all from Santa Cruz); phosphoJNK(Thr183/Tyr185)(9251), $\quad$ phospho-c-Jun(Ser63)
(9261S) and phospho-c-Jun (Ser73) (9164S) (all from Cell Signaling Technology).

\section{Electrophoretic mobility shift assay (EMSA)}

Nuclear extracts were prepared by the use of NE-PER Nuclear and Cytoplasmic Extraction Kit (Cat. No.78833, Pierce) in accordance with the manufacturer's protocol. The protein concentration in nuclear extracts was determined using the BCA protein assay reagent (Cat. No.23228, Pierce) and EMSAs were carried out using aliquots containing equal amounts of protein. EMSA analysis was performed using the LightShift ${ }^{\mathrm{TM}}$ Chemiluminescent EMSA Kit (Cat. No.20148, Pierce) following the manufacturer's instructions. The reaction mixtures $(20 \mu \mathrm{l})$ containing about $10 \mu \mathrm{g}$ nuclear extracts were incubated with 2 $\mathrm{nmol} / \mathrm{L}$ of the biotin-labeled double-stranded oligonucleotide probes in reaction buffer (Pierce) for $20 \mathrm{~min}$ at room temperature. Samples were subjected to electrophoresis in 5\% nondenaturing polyacrylamide gel and transferred to Biodyne ${ }^{\mathrm{TM}}$ B Nylon membrane (Cat. No.77016, Pierce). For competition analyses, 200-fold excess of the unlabeled wild-type or mutant or nonspecific probe was included in the binding reaction. For antibody supershift experiments, the reaction mixtures were preincubated with $2 \mu \mathrm{g}$ of p50(sc-8414X), p52(sc-298X), p65(sc-8008X), c-Rel(sc-272X), RelB(sc-226X), c-Jun(sc$44 \mathrm{X}), \mathrm{c}-\mathrm{Fos}(\mathrm{sc}-52 \mathrm{X})$ and rabbit $\operatorname{IgG}(\mathrm{sc}-2027)$ antibody (all from Santa Cruz) at room temperature for $1 \mathrm{hr}$. The complementary oligonucleotides used as probes or competitors were listed below: the human $\kappa N F-\kappa B$ oligonucleotides used were 5'-ccagagggggatttccaagaggcca-3' and 5'tggcctcttggaaatcccctctgg-3', derived from the sequence of the NF-kB site within the human kappa intron enhancer. The human KAP-l oligonucleotides used were 5 '-gctttccttgactcagccgctgcc-3' and 5'-ggcagcggctgagtcaaggaaagc-3', derived from the AP- 1 sequence 320 bp 3 ' of the $\kappa N F-\kappa B$ site. The nonspecific oligonucleotides used as competitor DNA for $\kappa N F-\kappa B$ and $\kappa A P-1$ were $\kappa A P-l$ and $\kappa N F-\kappa B$ oligonucleotides, respectively. The mutated $\kappa \mathrm{NF}-\kappa \mathrm{B}$ oligonucleotides used were 5 -ccagagagagattgccaagaggcca-3' and 5 '-tggcctcttggcaatctctctctgg-3' (designated as mutкB). The mutated KAP-l oligonucleotides used were 5'-gctttcctggactcagccgctgcc-3' and 5'-ggcagcggctgagtccaggaaagc-3' (designated as mutAP-1). Binding sites were shown in bold type and mutated nucleotides were shown in bold italic. The mutated oligo probes for NF- $\mathrm{KB}$ and AP-1 binding sites in EMSAs were identical to those of the mutated sequences in the reporter gene constructs.

\section{Co-immunoprecipitation (Co-IP)}

Non-denatured nuclear proteins were purified using NEPER Nuclear and Cytoplasmic Extraction Kit (Cat. No.78833, Pierce) according to the manufacturer's instructions. Protein concentration was determined by BCA Assay Reagent (Cat. No.23228, Pierce). $200 \mu \mathrm{g}$ of 
nuclear extracts prepared from HNE2-LMP1 cells were mixed with $40 \mu \mathrm{l}$ protein A-Sepharose beads (Sigma) in the immunoprecipitation assay buffer ( $1 \times$ PBS, $0.5 \%$ Nonidet P-40, 0.5\% sodium deoxycholate, $0.1 \%$ SDS), incubated at $4{ }^{\circ} \mathrm{C}$ for $2 \mathrm{~h}$ with gentle agitation and centrifuged for $2 \mathrm{~min}$ at $2000 \mathrm{rpm}$ for preclearing. The recovered supernatant was incubated with $2 \mu \mathrm{g}$ of an antibody to a member of the complex in the presence of $1 \times$ protease inhibitors at $4{ }^{\circ} \mathrm{C}$ overnight with mild shaking. Then, 50 $\mu \mathrm{l}$ of protein A-Sepharose beads was added, and the incubation was continued for $2 \mathrm{~h}$ at $4^{\circ} \mathrm{C}$ with gentle shaking. Protein A-precipitated protein complex was recovered by brief centrifugation, followed by three times washes with immunoprecipitation assay buffer. The harvested beads resuspended in $30 \mu \mathrm{l}$ of $2 \times$ SDS PAGE sample buffer were boiled for $5 \mathrm{~min}$ to release the bound protein. The samples were then analyzed by Western blot with a specific antibody to another member of the complex. A $20 \mu \mathrm{g}$ aliquot of nuclear extract was used as an input control. The same membrane was stripped by incubating at $50^{\circ} \mathrm{C}$ for half an hour in stripping buffer [100 mM $\beta$-mercaptoethanol, 2\% (wt/vol) sodium dodecyl sulfate and $62.5 \mathrm{mM}$ Tris-HCl ( $\mathrm{pH} \mathrm{6.8)]} \mathrm{and} \mathrm{reprobed} \mathrm{with} \mathrm{the} \mathrm{corresponding}$ IP antibody.

\section{Chromatin immunoprecipitation (ChIP) assay}

ChIP was performed using the ChIP assay kit (Upstate Biotechnology, Lake Placid, NY) and was then conducted according to the manufacturer's recommendations. Briefly, formaldehyde solution was added directly to HNE2-LMP1 cells at a final concentration of $1 \%$ at room temperature for $10 \mathrm{~min}$. Then the cells was neutralized with glycine at room temperature for $5 \mathrm{~min}$ and washed twice with ice-cold $1 \times$ phosphate-buffered saline containing protease inhibitors. The cells were lysed by SDS lysis buffer with protease inhibitors. Chromatin in the lysate $(350 \mu \mathrm{l})$ was sheared by sonication with a Branson Sonifier Cell disruptor B15 (output control 4, duty cycle 40\%), with 14 cycles of 20-second pulses and 20-second intervals to an average length of $500 \mathrm{bp}$ as determined by $2 \%$ agarose gel electrophoresis. The suspension was precleared with salmon sperm DNA/protein A/agarose-50\% slurry for $1 \mathrm{~h}$ at $4^{\circ} \mathrm{C}$. After "precleared" the chromatin, a small aliquot $(10 \mu \mathrm{l})$ was saved as "input DNA" for PCR analysis later. Other each $100 \mu \mathrm{l}$ aliquots of sheared crosslinked chromatin were incubated with $2 \mu \mathrm{g}$ each of antibodies p50(sc-8414X), p52(sc-298X), p65(sc-8008X), cRel(sc-272X), RelB(sc-226X), c-Jun(sc-44X), c-Fos(sc$52 \mathrm{X})$, rabbit IgG(sc-2027) (Santa Cruz), or no Ab overnight at $4{ }^{\circ} \mathrm{C}$ with mild shaking. The immune complexes were incubated with salmon sperm DNA/protein A/agarose-50\% slurry with mild shaking for $2 \mathrm{~h}$ at $4{ }^{\circ} \mathrm{C}$, washed, and eluted. Cross-links were reversed by $5 \mathrm{M} \mathrm{NaCl}$. After proteinase $\mathrm{K}$ digestion, DNA in samples was phenol extracted, ethanol precipitated, and resuspended in $50 \mu \mathrm{l}$ of $\mathrm{ddH}_{2} \mathrm{O}$. Two microliters of DNA solution was used for 36 cycles of PCR amplification. PCR products were analyzed by electrophoresis on a $2 \%$ agarose gel and visualized by ethidium bromide staining. The following primers were used in the ChIP assays: human $\mathrm{iE}_{\mathrm{\kappa}}$ enhancer including the NF-кB-binding region, 5'-ctactgctctcccacccaac-3' and 5'-tgcagcaattttcagccata-3'(159 bp); the AP-1-binding region located downstream the human $\mathrm{iE}_{\mathrm{\kappa}}$ enhancer, 5'gcctgttatccagcacagt-3' and 5'-tgcatgctttctgaccttg-3'(188 bp).

\section{Statistical analysis}

All statistical calculations were performed with the statistical software program SPSS ver.12.0. Differences between various groups were evaluated by the Student's $t$ test. The difference was of statistical significance, when $\mathrm{P}<0.05$.

\section{Abbreviations}

EBV: Epstein-Barr virus; NPC: nasopharyngeal carcinoma; LMP1: latent membrane protein $1 ;$ NF- $\mathrm{B}$ : Nuclear factor kappa B; AP-1: activating protein-1; JNK: c-Jun N-terminal kinase; Ig: immunoglobulin; $\mathrm{C}_{\mathrm{\kappa}}$ region: kappa gene constant region; $\mathrm{J}_{\mathrm{\kappa}}$ region: kappa gene joining region; $\mathrm{iE}_{\mathrm{\kappa}}$ : immunoglobulin kappa intron enhancer; 3 ' $\mathrm{E}_{\mathrm{\kappa}}$ : immunoglobulin kappa 3' enhancer; EMSA: electrophoretic mobility shift assays; Co-IP: co-immunoprecipitation; ChIP: chromatin immunoprecipitation; TRAF: tumor necrosis factor receptor associated factor.

\section{Competing interests}

The authors declare that they have no competing interests.

\section{Authors' contributions}

HDL carried out all experiments and drafted the manuscript. HZ, ZD, DSH participated in the design of the study and assisted with the reporter gene analysis. SFL, ZJL participated in the statistical analysis. ML, XYD contributed in the design of the study and data interpretation. ZLW, MT, YS, WY assisted with the construction of luciferase reporter plasmids and participated in the sequence alignment. YC conceived of the study and participated in the design and coordination. All authors read and approved the final manuscript.

\section{Acknowledgements}

We thank Prof. NingZhi Xu (Peking Union Medical College, Chinese Academy of Medical Sciences) for their kind advice. This work was supported State Key Basic Research and Development Plan (973) of the Ministry of Science and Technology of China (No. 2004CB5 I 8703), National High Technology Research and Development Program (863) of China (No. 2006AA02A404) and National Nature Science Foundation of China (No.30471968, No.30973399).

\section{References}

I. Liu HD, Zheng H, Li M, Hu DS, Tang M, Cao Y: Upregulated expression of kappa light chain by Epstein-Barr virus encoded latent membrane protein $I$ in nasopharyngeal car- 
cinoma cells via NF-kappaB and AP-I pathways. Cell Signal 2007, 19:419-427.

2. Okabe H, Satoh S, Kato T, Kitahara O, Yanagawa R, Yamaoka Y, Tsunoda T, Furukawa Y, Nakamura Y: Genome-wide analysis of gene expression in human hepatocellular carcinomas using CDNA microarray: identification of genes involved in viral carcinogenesis and tumor progression. Cancer Res 200I, 6I:2 I 29-2I37.

3. Kimoto $Y$ : Expression of heavy-chain constant region of immunoglobulin and $\mathrm{T}$-cell receptor gene transcripts in human non-hematopoietic tumor cell lines. Genes Chromosomes Cancer 1998, 22:83-86.

4. Li J, Tan C, Xiang Q, Zhang X, Ma J, Wang JR, Yang J, Li W, Shen SR, Liang S, Li G: Proteomic detection of changes in protein synthesis induced by NGX6 transfected in human nasopharyngeal carcinoma cells. J Protein Chem 200I, 20:265-27I.

5. Qiu X, Zhu X, Zhang L, Mao Y, Zhang J, Hao P, Li G, Lv P, Li Z, Sun $X$, et al:: Human epithelial cancers secrete immunoglobulin $\mathbf{g}$ with unidentified specificity to promote growth and survival of tumor cells. Cancer Res 2003, 63:6488-6495.

6. Xiao T, Ying W, Li L, Hu Z, Ma Y, Jiao L, Ma J, Cai Y, Lin D, Guo S, et al.: An approach to studying lung cancer-related proteins in human blood. Mol Cell Proteomics 2005, 4: I480- I 486.

7. Chen Z, Gu J: Immunoglobulin G expression in carcinomas and cancer cell lines. Faseb J 2007, 21:293I-2938.

8. Zhu X, Li C, Sun X, Mao Y, Li G, Liu X, Zhang Y, Qiu X: Immunoglobulin mRNA and protein expression in human oral epithelial tumor cells. Appl Immunohistochem Mol Morphol 2008, 16:232-238.

9. Huang J, Sun X, Mao Y, Zhu X, Zhang P, Zhang L, Du J, Qiu X: Expression of immunoglobulin gene with classical V-(D)-J rearrangement in mouse brain neurons. Int J Biochem Cell Biol 2008, 40:1604-16I5

10. Li M, Feng DY, Ren W, Zheng L, Zheng H, Tang M, Cao Y: Expression of immunoglobulin kappa light chain constant region in abnormal human cervical epithelial cells. Int J Biochem Cell Biol 2004, 36:2250-2257.

II. Pongubala JM, Atchison ML: Activating transcription factor I and cyclic AMP response element modulator can modulate the activity of the immunoglobulin kappa 3' enhancer. J Biol Chem 1995, 270:10304-10313.

12. Sen R: NF-kappaB and the immunoglobulin kappa gene enhancer. J Exp Med 2004, 200:1099-11 02.

13. Pongubala JM, Atchison ML: PU.I can participate in an active enhancer complex without its transcriptional activation domain. Proc Natl Acad Sci USA 1997, 94:127-132.

14. Meyer KB, Ireland J: Activation of the immunoglobulin kappa 3' enhancer in pre-B cells correlates with the suppression of a nuclear factor binding to a sequence flanking the active core. Nucleic Acids Res 1994, 22: 1576-1582.

15. Staudt LM, Lenardo MJ: Immunoglobulin gene transcription. Annu Rev Immunol I99I, 9:373-398.

16. Lenardo M, Pierce JW, Baltimore D: Protein-binding sites in Ig gene enhancers determine transcriptional activity and inducibility. Science 1987, 236:1573-1577.

17. Izumi KM: Epstein-Barr virus signal transduction and B-lymphocyte growth transformation. Prog Mol Subcell Biol 2004, 36:269-288.

18. Eliopoulos AG, Gallagher NJ, Blake SM, Dawson CW, Young LS: Activation of the $\mathrm{p} 38$ mitogen-activated protein kinase pathway by Epstein-Barr virus-encoded latent membrane protein I coregulates interleukin-6 and interleukin-8 production. J Biol Chem 1999, 274:16085-16096.

19. Gires O, Kohlhuber F, Kilger E, Baumann M, Kieser A, Kaiser C, Zeidler R, Scheffer B, Ueffing M, Hammerschmidt W: Latent membrane protein I of Epstein-Barr virus interacts with JAK3 and activates STAT proteins. Embo J 1999, 18:3064-3073.

20. Hammarskjold ML, Simurda MC: Epstein-Barr virus latent membrane protein transactivates the human immunodeficiency virus type I long terminal repeat through induction of NFkappa B activity. J Virol 1992, 66:6496-650 I.

21. Mainou BA, Everly DN Jr, Raab-Traub N: Epstein-Barr virus latent membrane protein I CTARI mediates rodent and human fibroblast transformation through activation of PI3K. Oncogene 2005, 24:6917-6924.
22. Roberts ML, Cooper NR: Activation of a ras-MAPK-dependent pathway by Epstein-Barr virus latent membrane protein $I$ is essential for cellular transformation. Virology 1998, 240:93-99.

23. Song $X$, Tao YG, Deng XY, Jin X, Tan YN, Tang M, Wu Q, Lee LM, Cao Y: Heterodimer formation between c-Jun and Jun $B$ proteins mediated by Epstein-Barr virus encoded latent membrane protein I. Cell Signal 2004, I6: I I53-I I62.

24. Li HP, Chang YS: Epstein-Barr virus latent membrane protein I: structure and functions. J Biomed Sci 2003, 10:490-504.

25. Uchida J, Yasui T, Takaoka-Shichijo Y, Muraoka M, Kulwichit W, RaabTraub N, Kikutani H: Mimicry of CD40 signals by Epstein-Barr virus LMPI in B lymphocyte responses. Science 1999, 286:300-303.

26. Van Kooten C, Banchereau J: CD40-CD40 ligand: a multifunctional receptor-ligand pair. Adv Immunol 1996, 6 I: I-77.

27. Grant PA, Andersson T, Neurath MF, Arulampalam V, Bauch A, Muller R, Reth M, Pettersson S: A T cell controlled molecular pathway regulating the IgH locus: CD40-mediated activation of the IgH 3' enhancer. Embo J 1996, 15:669I-6700.

28. Sen $R$, Baltimore $D$ : Multiple nuclear factors interact with the immunoglobulin enhancer sequences. Cell 1986, 46:705-716.

29. Pierce JW, Lenardo M, Baltimore D: Oligonucleotide that binds nuclear factor NF-kappa B acts as a lymphoid-specific and inducible enhancer element. Proc Natl Acad Sci USA 1988, 85: | $482-\mid 486$.

30. Queen C, Stafford J: Fine mapping of an immunoglobulin gene activator. Mol Cell Biol 1984, 4:1042-1049.

31. Schanke JT, Marcuzzi A, Podzorski RP, Van Ness B: An AP I binding site upstream of the kappa immunoglobulin intron enhancer binds inducible factors and contributes to expression. Nucleic Acids Res 1994, 22:5425-5432.

32. Lars N, Paschalis S: The human I alpha I and I alpha 2 germline promoter elements: proximal positive and distal negative elements may regulate the tissue specific expression of $\mathrm{C}$ alpha I and C alpha 2 germline transcripts. Int Immunol I993, 5:27I-282.

33. Wittekindt NE, Hortnagel K, Geltinger C, Polack A: Activation of c-myc promoter $P I$ by immunoglobulin kappa gene enhancers in Burkitt lymphoma: functional characterization of the intron enhancer motifs kappaB, E box $I$ and $E$ box 2, and of the 3' enhancer motif PU. Nucleic Acids Res 2000, 28:800-808.

34. Nelms K, Hromas R, Van Ness B: Identification of a second inducible DNA-protein interaction in the kappa immunoglobulin enhancer. Nucleic Acids Res 1990, 18:1037-1043.

35. Gurova KV, Hill JE, Guo C, Prokvolit A, Burdelya LG, Samoylova E, Khodyakova AV, Ganapathi R, Ganapathi M, Tararova ND, et al.: Small molecules that reactivate $\mathrm{p} 53$ in renal cell carcinoma reveal a NF-kappaB-dependent mechanism of $\mathrm{p} 53$ suppression in tumors. Proc Natl Acad Sci USA 2005, 102:17448-17453.

36. Ding L, Li LL, Yang J, Tao YG, Ye M, Shi Y, Tang M, Yi W, Li XL, Gong JP, Cao Y: Epstein-Barr virus encoded latent membrane protein I modulates nuclear translocation of telomerase reverse transcriptase protein by activating nuclear factorkappaB p65 in human nasopharyngeal carcinoma cells. Int J Biochem Cell Biol 2005, 37:188I-1889.

37. Kahlina K, Goren I, Pfeilschifter J, Frank S: p68 DEAD box RNA helicase expression in keratinocytes. Regulation, nucleolar localization, and functional connection to proliferation and vascular endothelial growth factor gene expression. J Biol Chem 2004, 279:44872-44882.

38. Zheng H, Li M, Liu H, Ren W, Hu DS, Shi Y, Tang M, Cao Y: Immunoglobulin alpha heavy chain derived from human epithelial cancer cells promotes the access of $S$ phase and growth of cancer cells. Cell Biol Int 2007, 3 I:82-87.

39. Demengeot J, Oltz EM, Alt FW: Promotion of V(D)J recombinational accessibility by the intronic $E$ kappa element: role of the kappa B motif. Int Immunol 1995, 7:1995-2003.

40. Perkins ND: Integrating cell-signalling pathways with NF-kappaB and IKK function. Nat Rev Mol Cell Biol 2007, 8:49-62.

41. Perkins ND: Oncogenes, tumor suppressors and p52 NF-kappaB. Oncogene 2003, 22:7553-7556.

42. Perkins ND, Agranoff $A B$, Pascal E, Nabel G]: An interaction between the DNA-binding domains of ReIA(p65) and SpI mediates human immunodeficiency virus gene activation. Mol Cell Biol 1994, 14:6570-6583. 
43. Hess J, Angel P, Schorpp-Kistner M: AP-I subunits: quarrel and harmony among siblings. J Cell Sci 2004, I I 7:5965-5973.

44. Karin M, Liu Z, Zandi E: AP-I function and regulation. Curr Opin Cell Biol 1997, 9:240-246.

45. Qi X, Borowicz S, Pramanik R, Schultz RM, Han J, Chen G: Estrogen receptor inhibits c-Jun-dependent stress-induced cell death by binding and modifying c-Jun activity in human breast cancer cells. J Biol Chem 2004, 279:6769-6777.

46. Andrew AS, Klei LR, Barchowsky A: AP-I-dependent induction of plasminogen activator inhibitor-I by nickel does not require reactive oxygen. Am J Physiol Lung Cell Mol Physiol 200I, 28I:L616-623.

47. Ho SN, Hunt HD, Horton RM, Pullen JK, Pease LR: Site-directed mutagenesis by overlap extension using the polymerase chain reaction. Gene 1989, 77:5I-59.

Publish with Bio Med Central and every scientist can read your work free of charge

"BioMed Central will be the most significant development for disseminating the results of biomedical research in our lifetime. "

Sir Paul Nurse, Cancer Research UK

Your research papers will be:

- available free of charge to the entire biomedical community

- peer reviewed and published immediately upon acceptance

- cited in PubMed and archived on PubMed Central

- yours - you keep the copyright

Submit your manuscript here:

http://www.biomedcentral.com/info/publishing_adv.asp
BioMedcentral 